\title{
A Review on Comparative Remarks, Performance Evaluation and Improvement Strategies of Quadrotor Controllers
}

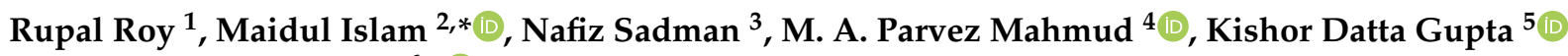 \\ and Md Manjurul Ahsan $6, *$ (D) \\ 1 Department of Mechatronics Engineering, International Islamic University Malaysia, \\ Kuala Lumpur 53100, Malaysia; rupal.roy@live.iium.edu.my \\ 2 Department of Aerospace Engineering, RMIT University, Melbourne, VIC 3001, Australia \\ 3 Silicon Orchard Ltd., Dhaka 1215, Bangladesh; nafiz@siliconorchard.com \\ 4 School of Engineering, Deakin University, Geelong, VIC 3216, Australia; m.a.mahmud@deakin.edu.au \\ 5 Department of Computer Science, University of Memphis, Memphis, TN 38152, USA; kgupta1@memphis.edu \\ 6 School of Industrial and Systems Engineering, University of Oklahoma, Norman, OK 73019, USA \\ * Correspondence: mislam.dipu@gmail.com (M.I.); ahsan@ou.edu (M.M.A.)
}

check for

updates

Citation: Roy, R.; Islam, M.; Sadman, N.; Mahmud, M.A.P.;

Gupta, K.D.; Ahsan, M.M. A Review on Comparative Remarks,

Performance Evaluation and Improvement Strategies of Quadrotor Controllers. Technologies 2021, 9, 37. https://doi.org/10.3390/

technologies 9020037

Academic Editor: Mauro Iacono

Received: 8 April 2021

Accepted: 11 May 2021

Published: 17 May 2021

Publisher's Note: MDPI stays neutral with regard to jurisdictional claims in published maps and institutional affiliations.

Copyright: (c) 2021 by the authors. Licensee MDPI, Basel, Switzerland. This article is an open access article distributed under the terms and conditions of the Creative Commons Attribution (CC BY) license (https:/ / creativecommons.org/licenses/by/ $4.0 /)$.

\begin{abstract}
The quadrotor is an ideal platform for testing control strategies because of its non-linearity and under-actuated configuration, allowing researchers to evaluate and verify control strategies. Several control strategies are used, including Proportional-Integral-Derivative (PID), Linear Quadratic Regulator (LQR), Backstepping, Feedback Linearization Control (FLC), Sliding Mode Control (SMC), and Model Predictive Control (MPC), Neural Network, H-infinity, Fuzzy Logic, and Adaptive Control. However, due to several drawbacks, such as high computation, a large amount of training data, approximation error, and the existence of uncertainty, the commercialization of those control technologies in various industrial applications is currently limited. This paper conducts a thorough analysis of the current literature on the effects of multiple controllers on quadrotors, focusing on two separate approaches: (i) controller hybridization and (ii) controller development. Besides, the limitations of the previous works are discussed, challenges and opportunities to work in this field are assessed, and potential research directions are suggested.
\end{abstract}

Keywords: controller improvement; controller survey; hybrid control; linear control; learning based control; nonlinear control; quadrotor

\section{Introduction}

A quadrotor is an unmanned aerial vehicle (UAV) that manages its operation using cross-configured two pairs of opposite directional rotors. It takes flight by maintaining produced thrust and torque by rotors. The necessary actions can be characterized by the roll, pitch, yaw, and upward-downward thrust for quadrotor movement. However, Autopilot design for autonomous quadrotors is a difficult task that entails several interconnected components [1].

Multifarious applications of quadrotors among civilians and the military draw attention among researchers and practitioners to explore more. The civilian application includes aerial photography, an inspection of industrial pipelines, traffic monitoring, crop monitoring, fire detection, rescue operations, weather forecasting, news coverage, etc., whereas military application incorporates border patrolling, surveillance, and warfare [2].

Quadrotor offers fixed-pitch rotors and Vertical Take-Off Landing (VTOL). However, it is highly challenging to maneuver because the system is under-actuated with four inputs to control six outputs. Different control strategies have been developed to handle the procedure by considering application factors like high agility, smooth maneuverability, outdoor noise, disturbances, and payload. 
Several type of quadrotor controller have been introduced by the referenced literature, which includes Proportional-Integral-Derivative (PID), Linear Quadratic Regulator (LQR), Backstepping, Feedback Linearization Control (FLC), Sliding Mode Control (SMC), Model Predictive Control (MPC), Linear Quadratic Gaussian (LQG), Neural Network, H-infinity, Fuzzy Logic, and Adaptive Control. These controllers can be classified into three categories such as linear, nonlinear, and learning-based controller [3-5]. For instance, Mahony et al. (2012) provides a primer on modeling, estimation, and control for multirotor aerial vehicles, including the quadrotor configuration [6]. Zhang et al. (2014) provides a tutorial on platform configuration, modeling techniques, developing a detailed nonlinear model, analyzing aerodynamic effects, and identifying a quadrotor model [7]. However, much literature also introduces another type of controller known as the hybrid controller that includes two or more control strategies.

This study briefly introduces and analyses some commonly used controllers such as PID, LQR, Backstepping, FLC, SMC, MPC, Neural Network, H-infinity, Fuzzy Logic Adaptive Control for a quadrotor. This study's main contribution is a comprehensive discussion that includes the applications and the limitations of the controllers to provide a proper understanding that may help the user choose a suitable one. Moreover, the present study remarkably overcomes several shortcomings of the literature [2,5,8-13] especially in the performance evaluation, challenges and solutions of the controllers to a certain extent on the quadrotor platform based on past studies.

\subsection{Linear Control Techniques}

LQR control, PD or PID control, $\mathrm{H} \infty$ algorithm, and gain scheduling are the most commonly and conventionally applied linear control techniques. In the early 1970s, a full-scale helicopter, $\mathrm{CH}-53 \mathrm{~A}$, could achieve waypoints autonomously using a classical linear controller [5].

\subsubsection{PID Controller}

PID controller can be considered as one of the most widely used feedback controllers for quadrotors [14] because of its simplicity to design and low complexity in implementation on the system. Moreover, it shows high efficiency both in simulation and experimental work on the quadrotor platform. The great advantage of this controller is that it is not mandatory to know the dynamics of the quadrotor properly to design the controller where the trial and error approach for tuning gains of the controller can be sufficient. Studies show that many researchers successfully implemented PID controller on quadrotor platform [15-28]. Interestingly, Ghiglino et al. (2013) developed online self-tuning PID to tackle disturbances, whereas other types of PID perform offline optimization, which often very time-consuming [29]. Figure 1 illustrates a block diagram of a PID controller.

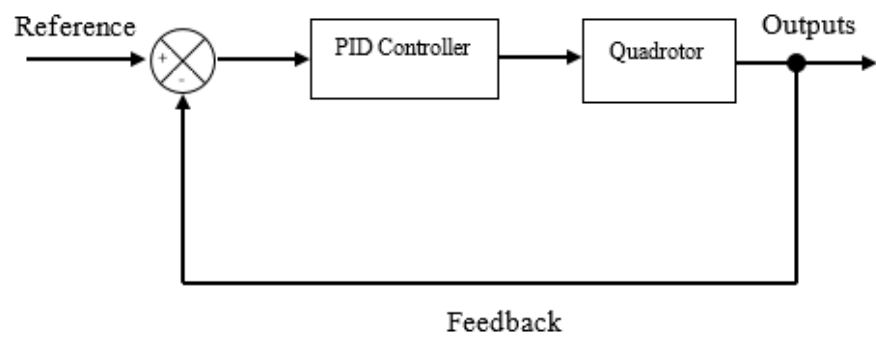

Figure 1. A block diagram of PID controller.

The classical PID controller is only applied with the linear model. This controller allows designing the controller according to the desired model performance. However, it becomes more challenging to design a well-performed PID controller when the model is nonlinear. The gain cannot be chosen systematically as the classical PID controller requires. 


\subsubsection{LQR Control}

Linear Quadratic Regulator (LQR) is a type of commonly used optimal linear controller for quadrotor as shown in Figure 2. This controller adopts a cost function minimizing approach, also known as the optimal control method, in order to compute the states of any system. LQR can offer a fast response, and it is easy to design. Referenced literature applied LQR on quadrotor platform in several cases [20,30-37]. However, in many cases, it was observed that LQR offers steady-state error during tracking $[15,38,39]$. Therefore, Alsharif et al. (2017) introduces LQI in order to overcome the steady-state error and stabilize the system when the system is affected by noise and uncertainty [40].

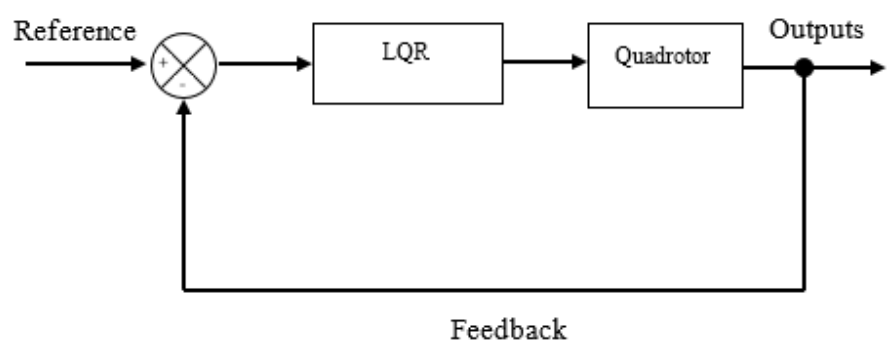

Figure 2. A block diagram of LQR.

LQR also requires a linear model to get an adequately controlled system, and it can handle multiple input and output simultaneously, unlike the PID controller. The main drawback of LQR compared to PID is that it often provides a steady-state error due to the lack of an integral part [41].

\subsection{3. $\mathrm{H \infty}$}

$\mathrm{H} \infty$ is a very popular control approach to ensure the robustness of the system among the linear controllers. Researchers prefer to use this control approach when a system includes uncertain parameters and unmolded dynamics. Interestingly, a study reports that it is able to overcome uncertainties up to $75 \%$ of the model [42]. Literature shows the implementations of the controller on the quadrotor platform in different ways. Some researchers use simple linear [43-45] while others introduce non-linearly [46-48]. Another group of researchers is interested in combining with other controllers in order to improve the performance of the controller when the system is surrounded by noise and disturbance $[47,49,50]$.

$\mathrm{H} \infty$ is a robust controller that is highly performed when system contains multivariables and states are cross-coupled. Notwithstanding, it requires a well-designed model to achieve satisfactory performance and high-level of mathematical understanding to develop [51].

\subsubsection{Gain-Scheduling}

A group of linear models is designed to improve a linear model's capabilities at some operating points. This model-based approach is known as gain scheduling. Gain scheduling can be considered as one of the successful strategies to deal with the nonlinear model. Literature report several studies where a gain-scheduling approach like PID improves both linear and nonlinear controllers [52-56], LQR [57], SMC [58,59] etc.

\subsection{Nonlinear Control Techniques}

As a linear model has some limitations like poor performance around different operating points and incapability of dealing with the nonlinear part of a model, several nonlinear control approaches have been developed. Nonlinear control approaches have been developed based on a nonlinear dynamic model that may incorporate model uncertainties like noise, disturbance and gust, unmodeled parameters, or dynamics and parameter 
variations. Feedback linearization, model predictive control, backstepping, sliding mode, and adaptive controller are commonly used nonlinear control techniques.

\subsubsection{Feedback Linearization}

In feedback linearization (FL), the state variables of a nonlinear dynamic system are transformed into a new coordinate system of a linear dynamic system using linear tools, and afterward, it is again transformed back to the original dynamic system through inverse transformation [5]. Several successful implementations of this controller are available in the literature [60-65]. R. Bonna and J. F. Camino (2015) used feedback linearization for trajectory tracking to control rotational and translational dynamics [66]. Freddi et al. (2014) designed a quadrotor model in any failure case of a rotor by using feedback linearization. In that work, two different loops were used where one was used for regulating trajectory, and another was used for modifying the desired trajectory that was succeeded in a simulation environment [67]. Abdellah Mokhtari et al. (2006) designed a feedback linearization with the observer in order to ensure robustness to the system with a minimum amount of sensors when the system is affected by wind [68]. A block diagram of FLC has been illustrated in Figure 3.

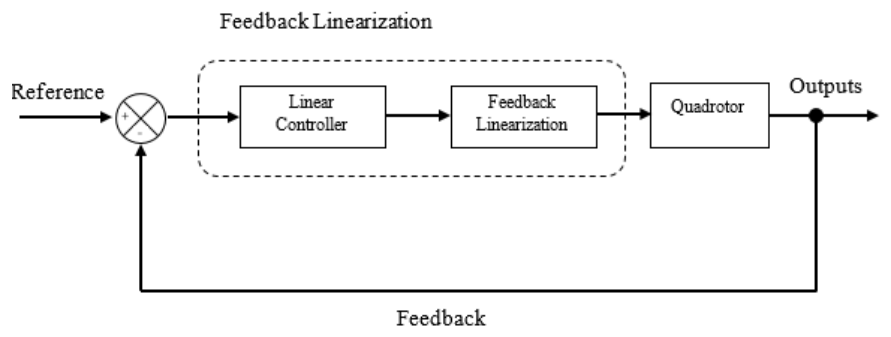

Figure 3. A block diagram of FLC.

A systematic framework for modeling a controller is the main advantage of feedback linearization. It is a well-performed controller when the difference between linear and nonlinear models is insignificant. However, it cannot guarantee a satisfactory response in the presence of model uncertainties and offer the functionality of constraints handling as well. Hence, the robustness of this controller is not always satisfactory $[2,69,70]$.

\subsubsection{Backstepping}

Backstepping is known as a recursive technique to control any under-actuated linear or nonlinear system Figure 4. It disseminates the controller into several steps and makes the system stabilized progressively [5]. It is useful when some states of the system are controlled by other states [71]. Notably, backstepping can offer promising performance when the dynamics and external disturbance are known precisely. Madani and Benallegue (2006) have applied the backstepping control approach based on Lyapunov theory to stabilize the quadcopter in the desired position and attitude. In that work, an under-actuated subsystem has been introduced to control horizontal position through roll and pitch angles, whereas a fully actuated subsystem is used to control vertical position through yaw and a propeller subsystem to control propeller forces [72]. Xing Huo et al. (2014) applied an integral backstepping controller to stabilize quadrotor attitude. In that work, the controller could ensure the promising performance of all the states of the system considering the external disturbances to the system in the simulation environment [73]. Zheng Fang and Weinan Gao (2011) advanced the earlier controller by adopting an additional feature that finally can be named as adaptive integral backstepping control algorithm in order to improve the robustness of the system in the presence of external disturbances on a quadrotor. The integral approaches can remove the steady-state error, minimize the response time, and control overshoot [74]. Niroumand et al. (2013) introduces fuzzy logic with integral backstepping for the improvement of robustness and better disturbance rejection [75]. 


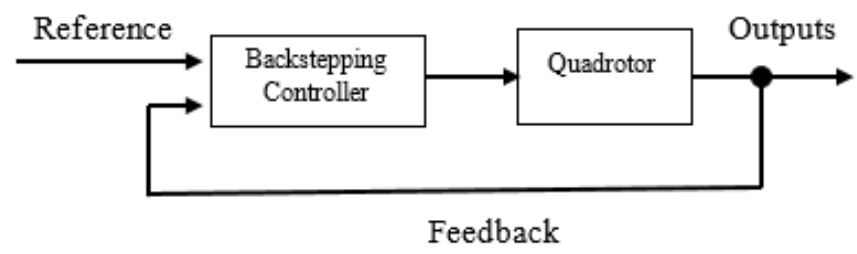

Figure 4. A block diagram of Backstepping.

Backstepping is one of the most chosen nonlinear control techniques that require a systematic procedure and follows recursive design methodology. It can outline the nonlinear terms in the system and, it does not require a precisely designed model, unlike feedback linearization. It can overcome the mismatched perturbations and can attain stability asymptotically. However, the main drawback of this controller is over-parameterization that implies its requirement of many parameters to give a satisfactory performance to the system that sometimes becomes very difficult to find out accurately $[73,76,77]$.

\subsubsection{Sliding Mode}

The sliding mode controller (SMC) is a switching control technique. In this control technique, the system states are commanded towards a suitably chosen desired surface known as the sliding surface, where system states remain on the body with the help of a properly designed control law [78]. Literature introduces several successes of simple sliding mode control for quadrotors [79]. R. Xu and U. Ozguner (2006) proposed a sliding mode control to stabilize the under-actuated subsystem of the quadrotor with a PID controller's help. They validated the robustness of the controller by dealing with parametric uncertainties [80]. Swamp (2016) introduced a second-order sliding mode control that was designed based on Lyapunov theory to stabilize the quadrotor. This second-order sliding mode controller demonstrated promising results comparing to the conventional sliding mode and ensures robustness as well [81]. A simple SMC has been portrayed in Figure 5.

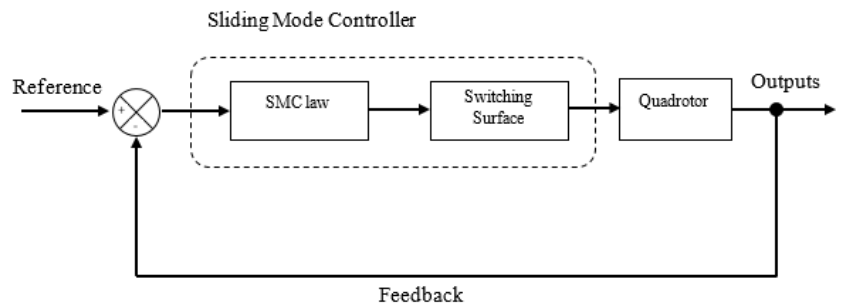

Figure 5. A block diagram of Sliding Mode Controller.

SMC technique has achieved great attention for designing robust controllers in highorder nonlinearity of any system under uncertainties. It is less sensitive to disturbances and parametric uncertainties that can ensure robustness to the system. However, it offers a chattering problem that happens because of continuous switching of the controlled model. As a result, it may provoke energy loss, unmodeled dynamics, and system instability that is hazardous for the system sometimes [79,82-84].

\subsubsection{Model Predictive Control}

Model Predictive Control (MPC) becomes one of the widespread controllers nowadays because of its capability in working with constraints and disturbances, predictive behavior, simplicity in tuning, and advanced performance with multi-variables at the same time. It is considered as a nonlinear control system that works on predicting future states and error [5]. MPC works on the basis of optimization where the cost function is minimized depending on the current control inputs and future time interval by handling the constraints of states and inputs [85]. Raffo et al. (2008) proposed an MPC to track the reference trajectory considering disturbances and integrated a nonlinear $\mathrm{H}$-infinity to obtain the robustness of the system in quadcopter [46]. In a previous study, MPC is applied to attain robust 
performance from the system under wind-gust disturbance conditions for attitude reference tracking in the quadcopter. The system could successfully track the reference points by using a single MPC technique where constraints have been considered at control inputs [86]. Patrick Bouffard et al. (2012) used Learning-Based Model Predictive Control (LBMPC) for robustness, and it is also demonstrated that the performance can be improved by updating the model online, which performs better than linear MPC [85]. A few experimental works on MPC are available in literature [56,85-89] while most of the time, nonlinear controllers with complexity are theoretical and simulation-based for quadrotor. A simple MPC has been shown in Figure 6.

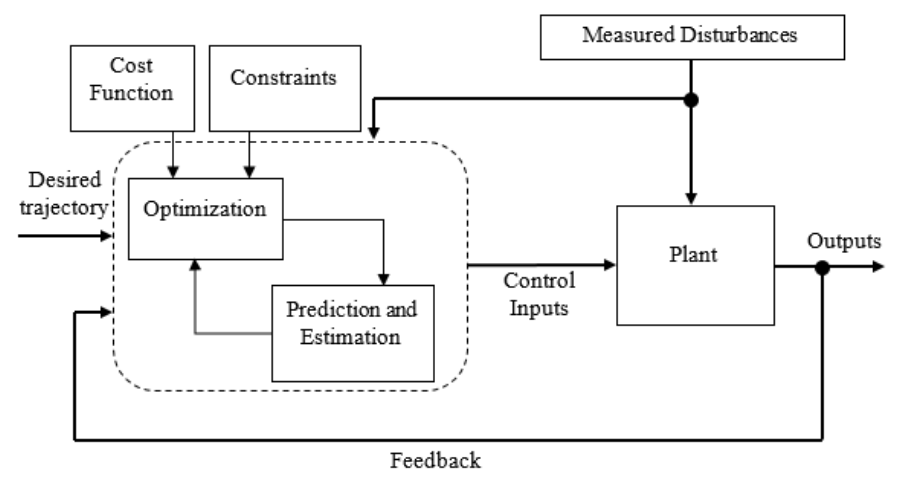

Figure 6. A block diagram of MPC.

MPC has been used in different processes of chemical industries and refineries for more than three decades. Currently, researchers show great interest in applying it in all types of complex controlling systems because of its versatile capability, as aforementioned [85].

\subsubsection{Adaptive Controller}

The adaptive controller offers a mechanism of parametric adjustability to control a system. Structurally this nonlinear controller includes two loops where one is used for the normal feedback process, and another one is used for parameter adjustment [90]. Adaptive control is widely applied in quadrotor, and most of the time, it is coupled with other controllers like neural network [91-93], SMC [94-96], fuzzy control [97], backstepping [98-101], gain-scheduling [102], LQR [103]. Koshkouei and Zinober (2000) combined multiple techniques like adaptive backstepping with sliding mode control in order to obtain the advantages of the controllers. The adaptive technique helps to overcome the problem of parametric uncertainty; Lyapunov theory that belongs to backstepping ensures the stability of the system, and sliding mode control tackles the unmeasured disturbances [104]. Interestingly, literature shows two types of adaptive control approach [105] based on design philosophies such as self-tuning regulator [106] and model reference [54,102,107-109]. Sadeghzadeh et al. (2011) introduced eight different ways to design model reference adaptive controller and they chose MIT rule to design the controller in their respective study [54]. In Figure 7, a block diagram of the adaptive controller has been portrayed.

The adaptive controller is mainly popular when the system is exploited with parametric uncertainty and model uncertainties like noise or disturbance [110]. There are five different ways for parameter adjustment of an adaptive controller like gain scheduling approach, auto-tuning, model reference, self-tuning control, and dual control. This controller is mainly used when process dynamics vary, the character of disturbances changes and engineering efficiency is concerned [90]. However, it becomes challenging to ensure robustness when the unknown parameters enter complicatedly in-process model [111]. Moreover, sometimes it performs slower in order to adapt the required parameters [90]. 


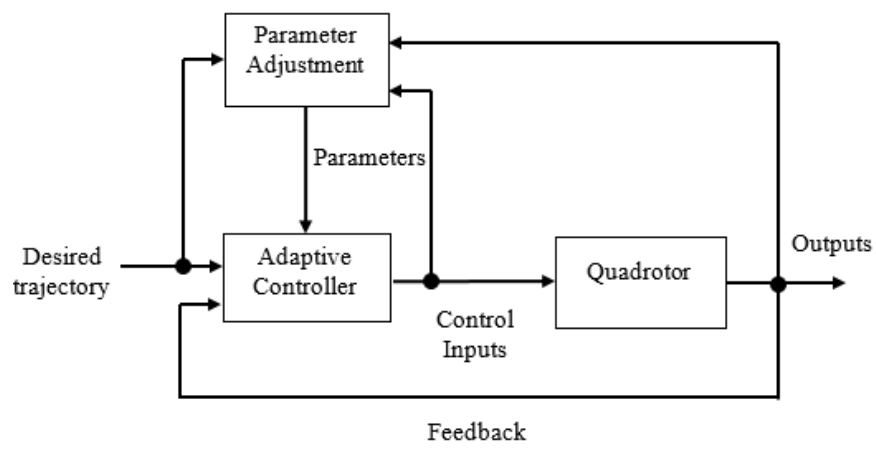

Figure 7. A block diagram of Adaptive Controller.

\subsection{Learning Based Control Techniques}

The learning-based controller is such a control technique that does not require an accurate and precise dynamic model, preferably some trials and flight data for training the system to control a quadrotor [5]. Fuzzy logic and neural network are considered under a learning-based controller.

\subsubsection{Fuzzy Logic Control}

Fuzzy logic control is generally introduced as a model-free and heuristic controller. It is considered as the successful outcome of fuzzy sets and systems. Successfully fuzzy controller proves its efficiency on complex nonlinear and nonanalytic systems [112]. In particular, the fuzzy controller has achieved popularity on quadrotor platforms both in standalone approach or combined with other control approaches. Santos et al. (2010) developed an intelligent fuzzy controller that could ensure satisfactory performance in the system's stability and precise movement. The controller parameters tuning with the help of inter-dependent variables were the most successful part of the work [113]. Coza and Macnab (2006) combined both adaptive and fuzzy controllers with stabilizing quadrotors under buffering wind with an unknown payload [97]. Three different types of fuzzy models [114] are very popular in the literature, such as Takagi-Sugeno (T-S) fuzzy model [115-117], Mamdani fuzzy model [118,119] and type-II fuzzy [120,121] that are being applied on a quadrotor.

Fuzzy control can be considered as one of the most suitable controllers for a nonlinear system with uncertainty. It has achieved great interest among the researchers as it offers the best-fitted solution when the system is complex, ill-defined, and uncertain. The most interesting part of the fuzzy controller is that it can offer the implementation of expert knowledge linguistically and can imitate human reasoning to simplify any complex system [114]. Nevertheless, it is not easy to design the linguistic control rule and analyze the system stability. In addition, it requires much time for parameter tuning [122,123], offers approximations errors [124-126] and shows the presence of unknown nonlinear functions $[126,127]$ when it is required to deal with under-actuated systems. The designer's expertise and good experience are also significant to make it functional properly [128].

\subsubsection{Neural Network Control}

An artificial neural network, inspired by human brain structure, has extensively been used in modern control engineering because of its ability to deal with intractable and cumbersome systems from extracted data through a systematic learning process. This controller can adapt itself to new environments and extract the required information from noisy, vague, and inconsistent data during the learning process [129]. Several successful attempts can be found in the literature of neural networks as quadrotor controllers [130-132]. A sample of the block diagram a Mamdani fuzzy controller is illustrated in Figure 8.

The neural network has achieved popularity because of its advantages like human reasoning for data analysis from incomplete and inconsistent information, high excellence in learning and adaptability, and robustness to the system [11,105]. Despite all these factors, 
it requires ample training and cannot ensure stability to the system always [11]. A review of different controllers has been addressed in Table 1.

Table 1. A review of different controllers.

\begin{tabular}{|c|c|c|}
\hline Controllers & Advantages & Disadvantages \\
\hline PID & $\begin{array}{l}\text { Easy to choose gain; Can overcome } \\
\text { steady-state error. }\end{array}$ & $\begin{array}{l}\text { Cannot handle constraints, noise and } \\
\text { disturbance; Cannot deal with multiple } \\
\text { inputs and outputs at the same time. }\end{array}$ \\
\hline LQR & $\begin{array}{l}\text { Can deal with multiple inputs } \\
\text { and outputs. }\end{array}$ & $\begin{array}{l}\text { Sometimes fails to overcome } \\
\text { steady-state error. }\end{array}$ \\
\hline $\mathbf{H} \infty$ & $\begin{array}{l}\text { Well performed when system is } \\
\text { multivariable with cross-coupling } \\
\text { among channels. }\end{array}$ & Requires well-designed model. \\
\hline Feedback Linearization & $\begin{array}{l}\text { Systemactic model framework; } \\
\text { Well-performed when linear and } \\
\text { nonlinear models are almost similar. }\end{array}$ & $\begin{array}{l}\text { Incapability of constraints handling and } \\
\text { model uncertainities, poor robustness. }\end{array}$ \\
\hline Backstepping & $\begin{array}{l}\text { Systematic and recursive designed; } \\
\text { Precisely designed model is not required; } \\
\text { Can handle nonlinearities to the system; } \\
\text { Can overcome mismatched perturbations } \\
\text { and ensures stability. }\end{array}$ & $\begin{array}{l}\text { Over-parameterization; Difficult to } \\
\text { choose proper parameters. }\end{array}$ \\
\hline SMC & $\begin{array}{l}\text { Well-performed in high-nonlinearity; } \\
\text { Less sensitivity in disturbances and } \\
\text { model uncertainities. }\end{array}$ & $\begin{array}{l}\text { Chattering problem sometimes create } \\
\text { system instability. }\end{array}$ \\
\hline MPC & $\begin{array}{l}\text { Predicts future behavior of the states; } \\
\text { Deals with multiple inputs and outputs } \\
\text { at the same time; can handle constraints } \\
\text { at inputs and outputs; Can overcome } \\
\text { noise and disturbances. }\end{array}$ & Slow in tracking. \\
\hline Adaptive & $\begin{array}{l}\text { Very effective when parameters are } \\
\text { unknown, dynamic and disturbance } \\
\text { model changes continuously; } \\
\text { Engineering efficiency is } \\
\text { comparatively satisfactory. }\end{array}$ & Takes time to adapt with the parameters. \\
\hline Fuzzy Logic & $\begin{array}{l}\text { Offers effective solution of a complex, } \\
\text { ill-defined and uncertain model; Does not } \\
\text { require accurate model. }\end{array}$ & $\begin{array}{l}\text { Difficult to design control rule and } \\
\text { system analysis; Takes linger time for } \\
\text { parameter tuning; Approximation error; } \\
\text { Presence of unkown nonlinear function. }\end{array}$ \\
\hline Neural Network & $\begin{array}{l}\text { Model free; Excellent in parallel } \\
\text { distributed processing, learning and } \\
\text { adaptation; Provide robustness to } \\
\text { the system. }\end{array}$ & $\begin{array}{l}\text { Requires ample of data for learning; Poor } \\
\text { system stability. }\end{array}$ \\
\hline
\end{tabular}

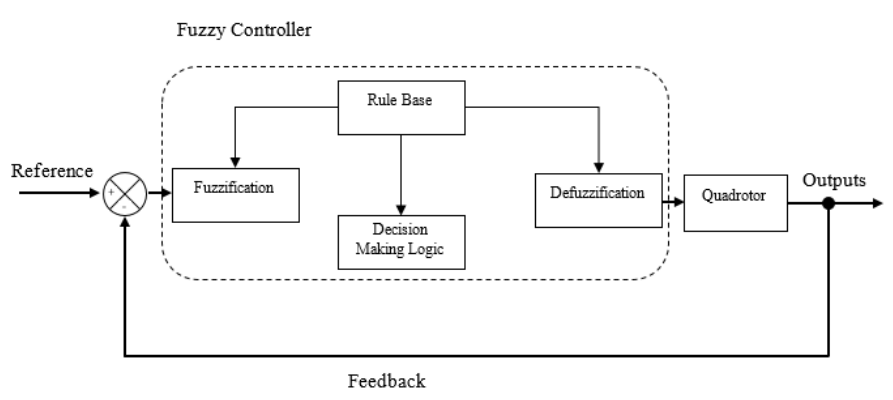

Figure 8. A block diagram of Fuzzy Controller (Mamdani Model). 


\section{Evaluation of Controllers}

\subsection{Stability of Nominal System}

Almost all the linear and nonlinear controllers can ensure system stability at the nominal state and ensure nominal performance as well. However, learning-based controllers like fuzzy and neural networks do not offer system stability at nominal conditions but can provide high maneuvering performance.

\subsection{Robustness}

In general, linear feedback controllers are not able to ensure the robustness of the system except $\mathrm{H} \infty$. Moreover, a few controllers like adaptive and MPC controllers can offer robust stability to the design and acceptable robust maneuvering performance among nonlinear controllers. In contrast, others are only able to provide robustness in performance. Interestingly, fuzzy and neural networks are not efficient enough to give robust stability to the system to ensure robustness in the system's maneuvering performance.

\subsection{Complexities}

In general, linear controllers are easy to implement on the system and that's why for experimental work, linear controllers are very famous among the researchers. On the other hand, nonlinear and learning-based controllers are, in general, medium to high in implementation complexity, albeit they are better at showing satisfactory performance than linear controllers.

\section{Challenges and Solution}

The earlier section describes the comparison among the controllers based on nominal stability, robustness, and implementation complexity. In the section, it is found that some controllers like LQR and PID are good at offering stability at nominal conditions while they are inefficient in ensuring robustness. Table 2 details the solutions from the referenced literature on quadrotor. On the other hand, learning-based controllers like fuzzy and neural networks are not able to ensure nominal stability, whereas they are highly efficient in robust performance. Therefore, hybrid controllers are initiated as a unit where multiple controllers can work altogether in order to ensure both nominal stability and robustness to a system. For instance, LQR turns into LQG (as shown in Figure 9) when LQR adopts Kalman Filter to establish a state observer and overcome the noise of the signal [133].

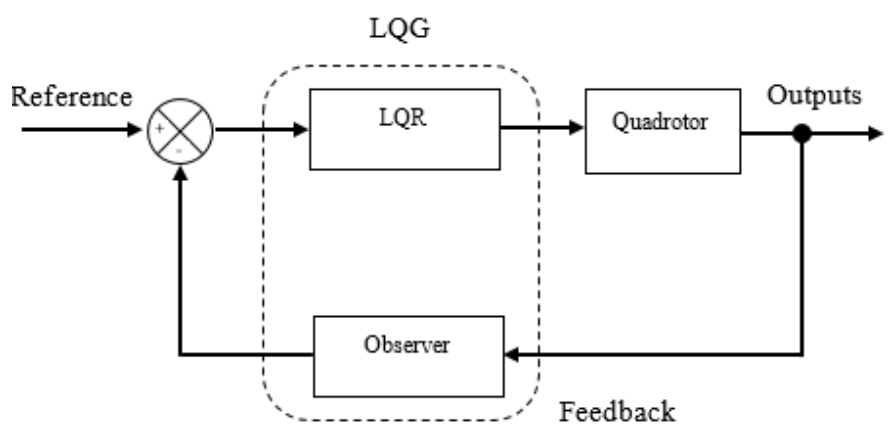

Figure 9. A block diagram of LQG.

Literature introduces some successful simulated performance and well-performed experimental works to overcome the incapacity and inefficiency of controllers. This study classifies the solutions based on literature into two types such as (a) a combination of other controllers with the existing controller or hybrid controller and (b) improvement of the current controller. Additionally, the improvement can be performed by adopting additional features or algorithms such as observer, estimator, integral, filter, compensator, etc., improvement of control algorithm by modification such as cascaded feature, selftuning, discretization, etc. or considering both approaches. 
Table 2. Performance improvement of controllers.

\begin{tabular}{|c|c|c|}
\hline Controllers & Controller Hybridization & Improvement of Existing Controller \\
\hline PID & $\begin{array}{l}\text { Ho [134], fuzzy [135-137], neural } \\
\text { network [138-141], feedback } \\
\text { linearization [142,143], } \\
\text { backstepping [63,144-146], } \\
\text { SMC [80,147,148]. }\end{array}$ & $\begin{array}{l}\text { Nonlinear PID [149-153], cascaded } \\
\text { PID [154,155], gradient optimization } \\
\text { based PID [156,157], particle swarm } \\
\text { optimization PID [158], self-tuning } \\
\text { PID [29,159], genetic algorithm based } \\
\text { PID [160,161], fractional PID [162], online } \\
\text { iterative learning [163]. }\end{array}$ \\
\hline LQR & $\begin{array}{l}\text { PID [41,41], adaptive control }[103,164] \text {, } \\
\text { feedback linearization [165], } \\
\text { backstepping [166], SMC [167], } \\
\text { fuzzy [168], neural network [169]. }\end{array}$ & $\begin{array}{l}\text { Full-order state observer [33], discrete } \\
\text { LQT [170], LQR with filter [24,171-174], } \\
\text { optimal trajectory planner [175], } \\
\text { distributed LQR [176], optimization [177], } \\
\text { extended LQR [178]. }\end{array}$ \\
\hline $\mathbf{H} \infty$ & MPC [50], PID [49,179], LQR [45]. & Requires well-designed model. \\
\hline Gain Scheduling & PID [52-56], LQR [57], SMC [58,59] & \\
\hline Feedback Linearization & $\begin{array}{l}\text { H } \infty \text { [180], LQR [165], adaptive [181,182], } \\
\text { backstepping [71], SMC [94]. }\end{array}$ & $\begin{array}{l}\text { Sliding mode observer [183], dynamic } \\
\text { extension [184], recursive Bayesian } \\
\text { filter [185], disturbance observer [186,187], } \\
\text { lie derivative [188], block control } \\
\text { algorithm [189], sliding mode } \\
\text { compensator [190]. }\end{array}$ \\
\hline Backstepping & $\begin{array}{l}\text { Neural network [191,192], feedback } \\
\text { linearization [144], sliding mode } \\
\text { control [72,193-199], fuzzy logic [200], } \\
\text { fuzzy and SMC [201], PID [202-204]. }\end{array}$ & $\begin{array}{l}\text { Integral with sliding mode [198,199], } \\
\text { integrator [205,206], Frenet-Serret } \\
\text { Theory-FST [145], nonlinear disturbance } \\
\text { observer [207], EKF [208,209], command } \\
\text { filter [210,211], command and auxiliary } \\
\text { filter [211], robust adaptive function [212], } \\
\text { particle swarm optimization [77,213], } \\
\text { extended state observer [214], Nussbaum } \\
\text { compensator [215], state transformation } \\
\text { approach [216], time-variation } \\
\text { formulation [217]. }\end{array}$ \\
\hline
\end{tabular}

PD [218,219], backstepping [72], feedback linearization [220], adaptive and backstepping [221].
Observer [222,223], integral [224,225], second order SMC [226,227], block control approach [228], adaptive control law [229], global fast dynamic terminal [230], fuzzy logic with gain switching [54], least square method [231], immersion and invariance method [232], adaptive control law [233], chattering elimination function [234], fractional order [235].

MPC PID [236], LQR [237], Ho [46],
SMC [238].
EKF [239], Gaussian Process model [240], Minimax optimization [241], convex optimization [242], disturbance observer [243] etc. or techniques such as piecewise affine $[86,244]$, model reduction [245], cascade feature [246], two layer approach [247], state-dependent coefficient representation [248], Fast Gradient method [249], Reinforcement learning [250]. 
Table 2. Cont.

\begin{tabular}{|c|c|c|}
\hline Adaptive & $\begin{array}{l}\text { Neural network [91-93], SMC [94-96], } \\
\text { fuzzy control [97], backstepping [98-101], } \\
\text { gain-scheduling [102], LQR [103]. }\end{array}$ & $\begin{array}{l}\text { Deadzone [251,252], parameter } \\
\text { projection [251,252], e-modification [253], } \\
\text { cerebellar algorithm [91,252], } \\
\text { L1 [110,254,255], command filtered } \\
\text { compensation [256], simpler state } \\
\text { feedback [257], linear matrix } \\
\text { inequality [258]. }\end{array}$ \\
\hline Fuzzy Logic & $\begin{array}{l}\text { PID }[22,135,259,260], \text { SMC }[58,201,261] \text {, } \\
\text { backstepping }[126,262], \text { neural } \\
\text { network [263-265], LQR [266]. }\end{array}$ & $\begin{array}{l}\text { Cell decomposition [267], parallel } \\
\text { distributed compensation }[266,268] \text {, } \\
\text { cascade [269], genetic algorithm }[270,271] \text {, } \\
\text { EKF [266]. }\end{array}$ \\
\hline Neural Network & $\begin{array}{l}\text { PID [99,272,273], adaptive [91,99,274], } \\
\text { backstepping [99,275], vision based } \\
\text { control [276], fuzzy [265]. }\end{array}$ & $\begin{array}{l}\text { Neural observer [93], neuro sliding mode } \\
\text { observer [277], high gain observer [278], } \\
\text { online [279] and offline [130] learning, } \\
\text { Nonlinear Auto Regressive eXogenous } \\
\text { input (NARX) model [280], } \\
\text { backpropagation [273,281], Radial Basis } \\
\text { Function [282], Modular Deep } \\
\text { Recurrent [283], direct inverse } \\
\text { control [90,139], dynamic } \\
\text { inversion [284,285]. }\end{array}$ \\
\hline
\end{tabular}

\section{Conclusions}

The present study outlines a review of different commonly applied controllers on a quadrotor. Different control techniques have their own specialties and limitations with their unique algorithms. Therefore, the applications and performance of the quadrotor decide the suitable controller.

Linear controllers always draw the attention of the researchers because of their simplicity in design and implementation with good experimental data. Nonlinear controllers offer features like robustness, noise and disturbance rejection, constraint handling at input and outputs, and more accurate trajectory tracking. However, a few experimental works are available in the literature using the nonlinear controller. Highly accurate parameter tuning and unmodeled parameters and dynamics make it difficult to achieve similar results from both the simulation and experiment. In the case of learning-based controllers, high computation, substantial training data, approximation error, and the presence of uncertainty are the challenges to be overcome in order to obtain satisfactory results though they are able to ensure promising performance when the system is troubled by uncertainty.

Significantly, this study discusses necessary solutions based on past studies to prevail over the available shortcomings through hybridization or improvement of an existing controller. Interestingly, some studies adopt multiple controllers and algorithms to ensure the promising performance of the controllers. Therefore, the required performance improvement of any controller depends on choosing a suitable controller, adoption of addition or modification of a controller or algorithm, or both the controller and algorithm. Future works include but are not limited to reviewing available modeling, navigation, and guidance of quadrotors.

Author Contributions: Conceptualization-R.R. and M.I.; methodology—R.R. and M.I.; validationN.S., K.D.G. and M.A.P.M.; formal analysis-M.M.A., N.S. and K.D.G.; investigation-K.D.G. and M.A.P.M.; writing—original draft preparation-R.R. and M.I.; writing—review and editing-M.M.A., N.S., K.D.G. and M.A.P.M.; visualization-N.S., M.M.A., K.D.G. and M.A.P.M. All authors have read and agreed to the published version of the manuscript.

Funding: This research received no external funding.

Institutional Review Board Statement: Not applicable. 
Informed Consent Statement: Not applicable.

Data Availability Statement: Not applicable.

Conflicts of Interest: The authors declare no conflict of interest.

\section{References}

1. L'afflitto, A.; Anderson, R.B.; Mohammadi, K. An introduction to nonlinear robust control for unmanned quadrotor aircraft: How to design control algorithms for quadrotors using sliding mode control and adaptive control techniques [focus on education]. IEEE Control Syst. Mag. 2018, 38, 102-121. [CrossRef]

2. Zulu, A.; John, S. A review of control algorithms for autonomous quadrotors. arXiv 2016, arXiv:1602.02622.

3. Junior, J.C.V.; De Paula, J.C.; Leandro, G.V.; Bonfim, M.C. Stability control of a quad-rotor using a PID controller. Braz. J. Instrum. Control 2013, 1, 15-20.

4. Habib, M.K.; Abdelaal, W.G.A.; Saad, M.S. Dynamic Modeling and Control of a Quadrotor Using Linear and Nonlinear Approaches. Ph.D. Thesis, American University, Cairo, IL, USA, 2014.

5. Kendoul, F. Survey of advances in guidance, navigation, and control of unmanned rotorcraft systems. J. Field Robot. 2012, 29, 315-378. [CrossRef]

6. Mahony, R.; Kumar, V.; Corke, P. Multirotor aerial vehicles: Modeling, estimation, and control of quadrotor. IEEE Robot. Autom. Mag. 2012, 19, 20-32. [CrossRef]

7. Zhang, X.; Li, X.; Wang, K.; Lu, Y. A survey of modelling and identification of quadrotor robot. Abstr. Appl. Anal. 2014, 2014, 320526. [CrossRef]

8. Li, Y.; Song, S. A survey of control algorithms for quadrotor unmanned helicopter. In Proceedings of the 2012 IEEE Fifth International Conference on Advanced Computational Intelligence (ICACI), Nanjing, China, 18-20 October 2012; pp. 365-369.

9. Gupte, S.; Mohandas, P.I.T.; Conrad, J.M. A survey of quadrotor unmanned aerial vehicles. In Proceedings of the 2012 Proceedings of IEEE Southeastcon, Orlando, FL, USA, 15-18 March 2012; pp. 1-6.

10. Nathan, P.T.; Almurib, H.A.; Kumar, T.N. A review of autonomous multi-agent quad-rotor control techniques and applications. In Proceedings of the 2011 4th International Conference on Mechatronics (ICOM), Kuala Lumpur, Malaysia, 17-19 May 2011; pp. 1-7.

11. Amin, R.; Aijun, L.; Shamshirband, S. A review of quadrotor UAV: Control methodologies and performance evaluation. Int. J. Autom. Control 2016, 10, 87-103. [CrossRef]

12. Deepak, B.; Singh, P. A survey on design and development of an unmanned aerial vehicle (quadcopter). Int. J. Intell. Unmanned Syst. 2016, 4, 70-106.

13. Li, L.; Sun, L.; Jin, J. Survey of advances in control algorithms of quadrotor unmanned aerial vehicle. In Proceedings of the 2015 IEEE 16th International Conference on Communication Technology (ICCT), Hangzhou, China, 18-20 October 2015 ; pp. 107-111.

14. Tayebi, A.; McGilvray, S. Attitude stabilization of a VTOL quadrotor aircraft. IEEE Trans. Control Syst. Technol. 2006, 14, 562-571. [CrossRef]

15. Bouabdallah, S.; Noth, A.; Siegwart, R. PID vs. LQ control techniques applied to an indoor micro quadrotor. In Proceedings of the 2004 IEEE/RSJ International Conference on Intelligent Robots and Systems (IROS)(IEEE Cat. No. 04CH37566), Sendai, Japan, 28 September-2 October 2004; Volume 3, pp. 2451-2456.

16. Li, J.; Li, Y. Dynamic analysis and PID control for a quadrotor. In Proceedings of the 2011 IEEE International Conference on Mechatronics and Automation, Beijing, China, 7-10 August 2011; pp. 573-578.

17. Salih, A.L.; Moghavvemi, M.; Mohamed, H.A.; Gaeid, K.S. Modelling and PID controller design for a quadrotor unmanned air vehicle. In Proceedings of the 2010 IEEE International Conference on Automation, Quality and Testing, Robotics (AQTR), Cluj-Napoca, Romania, 28-30 May 2010; Volume 1, pp. 1-5.

18. Salih, A.L.; Moghavvemi, M.; Mohamed, H.A.; Gaeid, K.S. Flight PID controller design for a UAV quadrotor. Sci. Res. Essays 2010, 5, 3660-3667.

19. Jun, L.; Yuntang, L. Modeling and PID control for a quadrotor. J. Liaoning Tech. Univ. Nat. Sci. 2012, 1. Available online: https:/ / en.cnki.com.cn/Article_en/CJFDTotal-GWDZ201216021.htm (accessed on 8 April 2021).

20. Khatoon, S.; Gupta, D.; Das, L. PID \& LQR control for a quadrotor: Modeling and simulation. In Proceedings of the 2014 International Conference on Advances in Computing, Communications and Informatics (ICACCI), Delhi, India, 24-27 September 2014; pp. 796-802.

21. Duc, M.N.; Trong, T.N.; Xuan, Y.S. The quadrotor MAV system using PID control. In Proceedings of the 2015 IEEE International Conference on Mechatronics and Automation (ICMA), Beijing, China, 2-5 August 2015; pp. 506-510.

22. Sharma, A.; Barve, A. Controlling of quad-rotor uav using pid controller and fuzzy logic controller. Int. J. Electr. Electron. Comput. Eng. 2012, 1, 38-41.

23. Wu, C.; Liu, X.; Yuan, X. Modeling and PID control for a quadrotor. Electron. Des. Eng. 2012, 16, 68-70.

24. Nuchkrua, T.; Parnichkun, M. Identification and optimal control of quadrotor. Sci. Technol. Asia 2012, 17, 36-53.

25. Rinaldi, F.; Gargioli, A.; Quagliotti, F. PID and LQ regulation of a multirotor attitude: Mathematical modelling, simulations and experimental results. J. Intell. Robot. Syst. 2014, 73, 33-50. [CrossRef] 
26. Khairuddin, I.M.; Majeed, A.P.; Lim, A.; M Jizat, J.A.; Jaafar, A.A. Modelling and PID Control of a Quadrotor Aerial Robot. In Advanced Materials Research; Trans Tech Publications Ltd.: Bäch, Switzerland, 2014; Volume 903, pp. 327-331.

27. Li, X.; Chen, Y.; Chen, P. Quadrotor Tracking Control Based on PID Algorithm. Comput. Meas. Control 2016, 24, 109-112.

28. Al Tahtawi, A.R.; Yusuf, M. Low-cost quadrotor hardware design with PID control system as flight controller. Telkomnika 2019, 17, 1923-1930. [CrossRef]

29. Ghiglino, P.; Forshaw, J.L.; Lappas, V.J. Online PID self-tuning using an evolutionary swarm algorithm with experimental quadrotor flight results. In Proceedings of the AIAA Guidance, Navigation, and Control (GNC) Conference, Boston, MA, USA, 19-22 August 2013; p. 5098.

30. Reyes-Valeria, E.; Enriquez-Caldera, R.; Camacho-Lara, S.; Guichard, J. LQR control for a quadrotor using unit quaternions: Modeling and simulation. In Proceedings of the CONIELECOMP 2013, 23rd International Conference on Electronics, Communications and Computing, Cholula, Mexico, 11-13 March 2013; pp. 172-178.

31. Tran, N.K.; Bulka, E.; Nahon, M. Quadrotor control in a wind field. In Proceedings of the 2015 International Conference on Unmanned Aircraft Systems (ICUAS), Denver, CO, USA, 9-12 June 2015; pp. 320-328.

32. Jafari, H.; Zareh, M.; Roshanian, J.; Nikkhah, A. An optimal guidance law applied to quadrotor using LQR method. Trans. Jpn. Soc. Aeronaut. Space Sci. 2010, 53, 32-39. [CrossRef]

33. Panomrattanarug, B.; Higuchi, K.; Mora-Camino, F. Attitude control of a quadrotor aircraft using LQR state feedback controller with full order state observer. In Proceedings of the SICE Annual Conference 2013, Nagoya, Japan, 14-17 September 2013; pp. 2041-2046.

34. Fan, B.; Sun, J.; Yu, Y. A LQR controller for a quadrotor: Design and experiment. In Proceedings of the 2016 31st Youth Academic Annual Conference of Chinese Association of Automation (YAC), Wuhan, China, 11-13 November 2016; pp. 81-86.

35. Budiyono, A.; Lee, G.; Kim, G.B.; Park, J.; Kang, T.; Yoon, K.J. Control system design of a quad-rotor with collision detection. Aircr. Eng. Aerosp. Technol. Int. J. 2015, 87, 59-66. [CrossRef]

36. Cowling, I.D.; Yakimenko, O.A.; Whidborne, J.F.; Cooke, A.K. A prototype of an autonomous controller for a quadrotor UAV. In Proceedings of the 2007 European Control Conference (ECC), Kos, Greece, 2-5 July 2007; pp. 4001-4008.

37. Faiz Ahmed, S.; Kadir, K.; Kamran Joyo, M. LQR based controller design for altitude and longitudinal movement of quad-rotor. J. Appl. Sci. 2016, 16, 588-593. [CrossRef]

38. Pounds, P.E.I. Design, Construction and Control of a Large Quadrotor Micro Air Vehicle. 2007. Available online: https: / / core.ac.uk/download/pdf/160609737.pdf (accessed on 30 April 2021).

39. Araar, O.; Aouf, N. Quadrotor control for trajectory tracking in presence of wind disturbances. In Proceedings of the 2014 UKACC International Conference on Control (CONTROL), Loughborough, UK, 9-11 July 2014; pp. 25-30.

40. Alsharif, M.A.; Arslantas, Y.E.; Hölzel, M.S. A comparison between advanced model-free PID and model-based LQI attitude control of a quadcopter using asynchronous android flight data. In Proceedings of the 2017 25th Mediterranean Conference on Control and Automation (MED), Valletta, Malta, 3-6 July 2017; pp. 1023-1028.

41. Argentim, L.M.; Rezende, W.C.; Santos, P.E.; Aguiar, R.A. PID, LQR and LQR-PID on a quadcopter platform. In Proceedings of the 2013 International Conference on Informatics, Electronics and Vision (ICIEV), Dhaka, Bangladesh, 17-18 May 2013; pp. 1-6.

42. Kang, T.; Yoon, K.J.; Ha, T.H.; Lee, G. H-infinity control system design for a quad-rotor. J. Inst. Control Robot. Syst. 2015, 21, 14-20. [CrossRef]

43. Gaitan, A.T.; Bolea, Y. Modeling and robust attitude control of a quadrotor system. In Proceedings of the 201310 th International Conference on Electrical Engineering, Computing Science and Automatic Control (CCE), Mexico City, Mexico, 30 September-4 October 2013; pp. 7-12.

44. Sorensen, A. Autonomous Control of a Miniature Quadrotor Following Fast Trajectories. Master's Thesis, Aalborg University, Aalborg, Denmark, 2010.

45. Araar, O; Aouf, N. Full linear control of a quadrotor UAV, LQ vs. Ho. In Proceedings of the 2014 UKACC International Conference on Control (CONTROL), Loughborough, UK, 9-11 July 2014; pp. 133-138.

46. Raffo, G.V.; Ortega, M.G.; Rubio, F.R. MPC with nonlinear $\mathcal{H} \infty$ control for path tracking of a quad-rotor helicopter. IFAC Proc. Vol. 2008, 41, 8564-8569. [CrossRef]

47. Raffo, G.V.; Ortega, M.G.; Rubio, F.R. Backstepping/nonlinear $\mathrm{H} \infty$ control for path tracking of a quadrotor unmanned aerial vehicle. In Proceedings of the 2008 American Control Conference, Seattle, WA, USA, 11-13 June 2008; pp. 3356-3361.

48. Jasim, W.; Gu, D. Ho for quadrotor attitude stabilization. In Proceedings of the 2014 UKACC International Conference on Control (CONTROL), Loughborough, UK, 9-11 July 2014; pp. 19-24.

49. Ortiz, J.P.; Minchala, L.I.; Reinoso, M.J. Nonlinear robust H-Infinity PID controller for the multivariable system quadrotor. IEEE Lat. Am. Trans. 2016, 14, 1176-1183. [CrossRef]

50. Chen, M.; Huzmezan, M. A combined mbpc/2 dof $\mathrm{h}$ infinity controller for a quad rotor uav. In Proceedings of the AIAA Guidance, Navigation, and Control Conference and Exhibit, Austin, TX, USA, 11-14 August 2003; p. 5520.

51. Méndez Cubillos, X.C.; de Souza, L.C.G. Using of H-infinity control method in attitude control system of rigid-flexible satellite. Math. Probl. Eng. 2009, 2009, 173145. [CrossRef]

52. Sadeghzadeh, I.; Abdolhosseini, M.; Zhang, Y.M. Payload drop application of unmanned quadrotor helicopter using gainscheduled pid and model predictive control techniques. In Proceedings of the International Conference on Intelligent Robotics and Applications; Springer: Berlin, Germany, 2012; pp. 386-395. 
53. Milhim, A.; Zhang, Y.; Rabbath, C.A. Gain scheduling based PID controller for fault tolerant control of quad-rotor UAV. In AIAA Infotech@ Aerospace 2010; Concordia University: Montreal, QC, Canada, 2010; p. 3530.

54. Sadeghzadeh, I.; Mehta, A.; Zhang, Y. Fault/damage tolerant control of a quadrotor helicopter UAV using model reference adaptive control and gain-scheduled PID. In Proceedings of the AIAA Guidance, Navigation, and Control Conference, Portland, OR, USA, 8-11 August 2011; p. 6716.

55. Sadeghzadeh, I.; Mehta, A.; Chamseddine, A.; Zhang, Y. Active fault tolerant control of a quadrotor uav based on gainscheduled pid control. In Proceedings of the 2012 25th IEEE Canadian Conference on Electrical and Computer Engineering (CCECE), Montreal, QC, Canada, 29 April-2 May 2012; pp. 1-4.

56. Sadeghzadeh, I.; Abdolhosseini, M.; Zhang, Y. Payload drop application using an unmanned quadrotor helicopter based on gain-scheduled PID and model predictive control. Unmanned Syst. 2014, 2, 39-52. [CrossRef]

57. Sawyer, S. Gain-Scheduled Control of a Quadcopter UAV. Master's Thesis, University of Waterloo, Waterloo, ON, Canada, 2015.

58. Yang, Y.; Yan, Y. Attitude regulation for unmanned quadrotors using adaptive fuzzy gain-scheduling sliding mode control. Aerosp. Sci. Technol. 2016, 54, 208-217. [CrossRef]

59. Yang, Y.; Yan, Y. Neural network gain-scheduling sliding mode control for three-dimensional trajectory tracking of robotic airships. Proc. Inst. Mech. Eng. Part I J. Syst. Control Eng. 2015, 229, 529-540. [CrossRef]

60. Freddi, A.; Lanzon, A.; Longhi, S. A feedback linearization approach to fault tolerance in quadrotor vehicles. IFAC Proc. Vol. 2011, 44, 5413-5418. [CrossRef]

61. Elsamanty, M.; Khalifa, A.; Fanni, M.; Ramadan, A.; Abo-Ismail, A. Methodology for identifying quadrotor parameters, attitude estimation and control. In Proceedings of the 2013 IEEE/ASME International Conference on Advanced Intelligent Mechatronics, Wollongong, NSW, Australia, 9-12 July 2013; pp. 1343-1348.

62. Ghandour, J.; Aberkane, S.; Ponsart, J.C. Feedback linearization approach for standard and fault tolerant control: Application to a quadrotor UAV testbed. J. Phys. Conf. Ser. 2014, 570, 082003. [CrossRef]

63. Azzam, A.; Wang, X. Quad rotor arial robot dynamic modeling and configuration stabilization. In Proceedings of the 2010 2nd International Asia Conference on Informatics in Control, Automation and Robotics (CAR 2010), Wuhan, China, 6-7 March 2010; Volume 1, pp. 438-444.

64. Jayakrishnan, H. Position and attitude control of a quadrotor UAV using super twisting sliding mode. IFAC-PapersOnLine 2016, 49, 284-289. [CrossRef]

65. Lotufo, M.; Colangelo, L.; Perez-Montenegro, C.; Novara, C.; Canuto, E. Embedded model control for UAV quadrotor via feedback linearization. IFAC-PapersOnLine 2016, 49, 266-271. [CrossRef]

66. Bonna, R.; Camino, J. Trajectory tracking control of a quadrotor using feedback linearization. In International Symposium on Dynamic Problems of Mechanics; University of Campinas: Sao Paulo, Brazil, 2015.

67. Lanzon, A.; Freddi, A.; Longhi, S. Flight control of a quadrotor vehicle subsequent to a rotor failure. J. Guid. Control Dyn. 2014, 37, 580-591. [CrossRef]

68. Mokhtari, A.; M'Sirdi, N.K.; Meghriche, K.; Belaidi, A. Feedback linearization and linear observer for a quadrotor unmanned aerial vehicle. Adv. Robot. 2006, 20, 71-91. [CrossRef]

69. Pop, C.I.; Dulf, E.H.; Mueller, A. Robust feedback linearization control for reference tracking and disturbance rejection in nonlinear systems. In Recent Advances in Robust Control-Novel Approaches and Design Methods; Technical University of Cluj: Cluj-Napoca, Romania, 2011; pp. 273-290.

70. Kurtz, M.J.; Henson, M.A. Feedback linearizing control of discrete-time nonlinear systems with input constraints. Int. J. Control 1998, 70, 603-616. [CrossRef]

71. Altug, E.; Ostrowski, J.P.; Mahony, R. Control of a quadrotor helicopter using visual feedback. In Proceedings of the 2002 IEEE International Conference on Robotics and Automation Cat. No. 02CH37292, Washington, DC, USA, 11-15 May 2002; Volume 1, pp. 72-77.

72. Madani, T.; Benallegue, A. Backstepping control for a quadrotor helicopter. In Proceedings of the 2006 IEEE/RSJ International Conference on Intelligent Robots and Systems, Beijing, China, 9-15 October 2006; pp. 3255-3260.

73. Huo, X.; Huo, M.; Karimi, H.R. Attitude stabilization control of a quadrotor UAV by using backstepping approach Math. Probl. Eng. 2014, 2014, 749803. [CrossRef]

74. Fang, Z.; Gao, W. Adaptive integral backstepping control of a micro-quadrotor. In Proceedings of the 20112 nd International Conference on Intelligent Control and Information Processing, Harbin, China, 25-28 July 2011; Volume 2, pp. $910-915$.

75. Niroumand, F.J.; Fakharian, A.; Seyedsajadi, M.S. Fuzzy integral backstepping control approach in attitude stabilization of a quadrotor UAV. In Proceedings of the 2013 13th Iranian Conference on Fuzzy Systems (IFSC), Qazvin, Iran, 27-29 August 2013; pp. 1-6.

76. Chung, C.W.; Chang, Y. Design of Adaptive Backstepping Controller for Systems with Mismatched Perturbations to Achieve Asymptotical Stability. Available online: https://digital-library.theiet.org/content/journals/10.1049/iet-cta_20050383 (accessed on 30 April 2021).

77. Mohd Basri, M.A.; Danapalasingam, K.A.; Husain, A.R. Design and optimization of backstepping controller for an underactuated autonomous quadrotor unmanned aerial vehicle. Trans. FAMENA 2014, 38, 27-44. 
78. Ben Ammar, N.; Bouallegue, S.; Haggege, J. Modeling and sliding mode control of a quadrotor unmanned aerial vehicle. In Proceedings of the 3rd International Conference on Automation, Control, Engineering and Computer Science; 2016 ; pp. 834-840. Available online: http:/ /ipco-co.com/PET_Journal/Acecs-2016/134.pdf (accessed on 30 April 2021).

79. Runcharoon, K.; Srichatrapimuk, V. Sliding mode control of quadrotor. In Proceedings of the 2013 The International Conference on Technological Advances in Electrical, Electronics and Computer Engineering (TAEECE), Konya, Turkey, 9-11 May 2013; pp. 552-557.

80. Xu, R.; Ozguner, U. Sliding mode control of a quadrotor helicopter. In Proceedings of the 45th IEEE Conference on Decision and Control, San Diego, CA, USA, 13-15 December 2006; pp. 4957-4962.

81. Sudhir; Swamp, A. Second order sliding mode control for quadrotor. In Proceedings of the 2016 IEEE First International Conference on Control, Measurement and Instrumentation (CMI), Kolkata, India, 8-10 January 2016; pp. 92-96.

82. Bendaas, I.; Naceri, F. A new method to minimize the chattering phenomenon in sliding mode control based on intelligent control for induction motor drives. Serbian J. Electr. Eng. 2013, 10, 231-246. [CrossRef]

83. Levant, A. Principles of 2-sliding mode design. Automatica 2007, 43, 576-586. [CrossRef]

84. Shtessel, Y.; Edwards, C.; Fridman, L.; Levant, A. Introduction: Intuitive theory of sliding mode control. In Sliding Mode Control and Observation; Springer: New York, NY, USA, 2014; pp. 1-42.

85. Bouffard, P. On-Board Model Predictive Control of a Quadrotor Helicopter: Design, Implementation, and Experiments; Technical Report; California Univ. Berkeley Dept. of Computer Sciences: Berkeley, CA, USA, 2012.

86. Alexis, K.; Nikolakopoulos, G.; Tzes, A. Experimental model predictive attitude tracking control of a quadrotor helicopter subject to wind-gusts. In Proceedings of the 18th Mediterranean Conference on Control and Automation, MED'10, Marrakech, Morocco, 23-25 June 2010; pp. 1461-1466.

87. Bangura, M.; Mahony, R. Real-time model predictive control for quadrotors. IFAC Proc. Vol. 2014, 47, 11773-11780. [CrossRef]

88. Dentler, J.; Kannan, S.; Mendez, M.A.O.; Voos, H. A real-time model predictive position control with collision avoidance for commercial low-cost quadrotors. In Proceedings of the 2016 IEEE conference on control applications (CCA), Buenos Aires, Argentina, 19-22 September 2016; pp. 519-525.

89. Jain, R.P.K. Transportation of Cable Suspended Load Using Unmanned Aerial Vehicles: A Real-Time Model Predictive Control Approach. 2015. Available online: https://www.semanticscholar.org/paper/Transportation-of-Cable-Suspended-Load-usingAerial-Jain/7ed8122da4716c9b58289abd79d82feeb60f0a3e (30 April 2021).

90. Åström, K.J.; Wittenmark, B. Adaptive Control; Courier Corporation: Chelmsford, MA, USA, 2013.

91. Nicol, C.; Macnab, C.; Ramirez-Serrano, A. Robust neural network control of a quadrotor helicopter. In Proceedings of the 2008 Canadian Conference on Electrical and Computer Engineering, Niagara Falls, ON, Canada, 4-7 May 2008; pp. $1233-1238$.

92. Li, S.; Wang, Y.; Tan, J.; Zheng, Y. Adaptive RBFNNs/integral sliding mode control for a quadrotor aircraft. Neurocomputing 2016, 216, 126-134. [CrossRef]

93. Boudjedir, H.; Bouhali, O.; Rizoug, N. Adaptive neural network control based on neural observer for quadrotor unmanned aerial vehicle. Adv. Robot. 2014, 28, 1151-1164. [CrossRef]

94. Lee, D.; Kim, H.J.; Sastry, S. Feedback linearization vs. adaptive sliding mode control for a quadrotor helicopter. Int. J. Control Autom. Syst. 2009, 7, 419-428. [CrossRef]

95. Mofid, O.; Mobayen, S. Adaptive sliding mode control for finite-time stability of quad-rotor UAVs with parametric uncertainties. ISA Trans. 2018, 72, 1-14. [CrossRef] [PubMed]

96. Islam, S.; Faraz, M.; Ashour, R.; Cai, G.; Dias, J.; Seneviratne, L. Adaptive sliding mode control design for quadrotor unmanned aerial vehicle. In Proceedings of the 2015 International Conference on Unmanned Aircraft Systems (ICUAS), Denver, CO, USA, 9-12 June 2015; pp. 34-39.

97. Coza, C.; Macnab, C.J. A new robust adaptive-fuzzy control method applied to quadrotor helicopter stabilization. In Proceedings of the NAFIPS 2006-2006 Annual Meeting of the North American Fuzzy Information Processing Society, Montreal, QC, Canada, 3-6 June 2006; pp. 454-458.

98. Huang, M.; Xian, B.; Diao, C.; Yang, K.; Feng, Y. Adaptive tracking control of underactuated quadrotor unmanned aerial vehicles via backstepping. In Proceedings of the 2010 American Control Conference, Baltimore, MD, USA, 30 June-2 July 2010 ; pp. 2076-2081.

99. Madani, T.; Benallegue, A. Adaptive control via backstepping technique and neural networks of a quadrotor helicopter. IFAC Proc. Vol. 2008, 41, 6513-6518. [CrossRef]

100. Morel, Y.; Leonessa, A. Direct adaptive tracking control of quadrotor aerial vehicles. In ASME International Mechanical Engineering Congress and Exposition; Parts A and B; ASME: Chicago, IL, USA, 2006; pp. 155-161. [CrossRef]

101. Fang, Z.; Gao, W. Adaptive backstepping control of an indoor micro-quadrotor. Res. J. Appl. Sci. Eng. Technol. 2012, 4, 4216-4226.

102. Orsag, M.; Korpela, C.M.; Bogdan, S.; Oh, P.Y. Hybrid adaptive control for aerial manipulation. J. Intell. Robot. Syst. 2014, 73, 693-707. [CrossRef]

103. Ghaffar, A.A.; Richardson, T. Model reference adaptive control and LQR control for quadrotor with parametric uncertainties. Int. J. Mech. Mechatron. Eng. 2015, 9, 244-250.

104. Koshkouei, A.J.; Zinober, A.S. Adaptive backstepping control of nonlinear systems with unmatched uncertainty. In Proceedings of the 39th IEEE Conference on Decision and Control (Cat. No. 00CH37187), Sydney, NSW, Australia, 12-15 December 2000; Volume 5, pp. 4765-4770. 
105. Jiang, Y.; Yang, C.; Ma, H. A review of fuzzy logic and neural network based intelligent control design for discrete-time systems. Discret. Dyn. Nat. Soc. 2016, 2016, 7217364. [CrossRef]

106. Yang, J.; Cai, Z.; Lin, Q.; Wang, Y. Self-tuning PID control design for quadrotor UAV based on adaptive pole placement control. In Proceedings of the 2013 Chinese Automation Congress, Changsha, China, 7-8 November 2013; pp. $233-237$.

107. Dydek, Z.T.; Annaswamy, A.M.; Lavretsky, E. Adaptive control of quadrotor UAVs: A design trade study with flight evaluations. IEEE Trans. Control Syst. Technol. 2012, 21, 1400-1406. [CrossRef]

108. Mohammadi, M.; Shahri, A.M. Adaptive nonlinear stabilization control for a quadrotor UAV: Theory, simulation and experimentation. J. Intell. Robot. Syst. 2013, 72, 105-122. [CrossRef]

109. Leitner, J.; Calise, A.; Prasad, J. Analysis of adaptive neural networks for helicopter flight control. J. Guid. Control Dyn. 1997, 20, 972-979. [CrossRef]

110. Zuo, Z.; Ru, P. Augmented L 1 adaptive tracking control of quad-rotor unmanned aircrafts. IEEE Trans. Aerosp. Electron. Syst. 2014, 50, 3090-3101. [CrossRef]

111. Hespanha, J.P.; Liberzon, D.; Morse, A.S. Overcoming the limitations of adaptive control by means of logic-based switching. Syst. Control Lett. 2003, 49, 49-65. [CrossRef]

112. Feng, G. A survey on analysis and design of model-based fuzzy control systems. IEEE Trans. Fuzzy Syst. 2006, 14, 676-697. [CrossRef]

113. Santos, M.; Lopez, V.; Morata, F. Intelligent fuzzy controller of a quadrotor. In Proceedings of the 2010 IEEE International Conference on Intelligent Systems and Knowledge Engineering, Hangzhou, China, 15-16 November 2010; pp. 141-146.

114. Huang, X.; Ralescu, A.L.; Gao, H.; Huang, H. A survey on the application of fuzzy systems for underactuated systems. Proc. Inst. Mech. Eng. Part I J. Syst. Control Eng. 2019, 233, 217-244. [CrossRef]

115. Rabhi, A.; Chadli, M.; Pégard, C. Robust fuzzy control for stabilization of a quadrotor. In Proceedings of the 2011 15th International Conference on Advanced Robotics (ICAR), Tallinn, Estonia, 20-23 June 2011; pp. 471-475.

116. Yazid, E.; Garratt, M.; Santoso, F. Position control of a quadcopter drone using evolutionary algorithms-based self-tuning for first-order Takagi-Sugeno-Kang fuzzy logic autopilots. Appl. Soft Comput. 2019, 78, 373-392. [CrossRef]

117. Castillo-Toledo, B.; Di Gennaro, S.; Jurado, F. Trajectory tracking for a quadrotor via fuzzy regulation. In Proceedings of the World Automation Congress 2012, Puerto Vallarta, Mexico, 24-28 June 2012; pp. 1-6.

118. Raharja, N.M.; Wahyunggoro, O.; Cahyadi, A.I. Altitude control for quadrotor with mamdani fuzzy model. In Proceedings of the 2015 International Conference on Science in Information Technology (ICSITech), Yogyakarta, Indonesia, 27-28 October 2015; pp. 309-314.

119. Pedro, J.O.; Mathe, C. Nonlinear direct adaptive control of quadrotor UAV using fuzzy logic technique. In Proceedings of the 2015 10th Asian Control Conference (ASCC), Kota Kinabalu, Malaysia, 31 May-3 June 2015; pp. 1-6.

120. Chen, X.; Li, D.; Xu, Z.; Bai, Y. Robust control of quadrotor MAV using self-organizing interval type-II fuzzy neural networks (SOIT-IIFNNs) controller. Int. J. Intell. Comput. Cybern. 2011, 4, 397-412. [CrossRef]

121. Chen, X.; Li, D.; Xu, Z.; Bai, Y. Gain adaptive sliding mode controller based on interval type-II fuzzy neural network designed for attitude control for micro aircraft vehicle. Int. J. Intell. Comput. Cybern. 2014, 7, 209-226. [CrossRef]

122. Lee, H.J.; Park, J.B.; Chen, G. Robust fuzzy control of nonlinear systems with parametric uncertainties. IEEE Trans. Fuzzy Syst. 2001, 9, 369-379.

123. Chen, C.L.; Chang, M.H. Optimal design of fuzzy sliding-mode control: A comparative study. Fuzzy Sets Syst. 1998, 93, 37-48. [CrossRef]

124. Taniguchi, T.; Tanaka, K.; Ohtake, H.; Wang, H.O. Model construction, rule reduction, and robust compensation for generalized form of Takagi-Sugeno fuzzy systems. IEEE Trans. Fuzzy Syst. 2001, 9, 525-538. [CrossRef]

125. Chen, Y.; Li, J.; Wang, K.; Ning, S. Robust trajectory tracking control of underactuated underwater vehicle subject to uncertainties. J. Mar. Sci. Technol. 2017, 25, 283-298.

126. Yacef, F.; Bouhali, O.; Hamerlain, M.; Rizoug, N. Observer-based adaptive fuzzy backstepping tracking control of quadrotor unmanned aerial vehicle powered by Li-ion battery. J. Intell. Robot. Syst. 2016, 84, 179-197. [CrossRef]

127. Baklouti, F.; Aloui, S.; Chaari, A. Adaptive fuzzy sliding mode tracking control of uncertain underactuated nonlinear systems: A comparative study. J. Control Sci. Eng. 2016, 2016. [CrossRef]

128. Mo, H.; Farid, G. Nonlinear and adaptive intelligent control techniques for quadrotor uav-a survey. Asian J. Control 2019, 21, 989-1008. [CrossRef]

129. Leondes, C.T. Neural Network Systems Techniques and Applications: Advances in Theory and Applications; Academic Press: New York, NY, USA, 1998.

130. Dunfied, J.; Tarbouchi, M.; Labonte, G. Neural network based control of a four rotor helicopter. In Proceedings of the 2004 IEEE International Conference on Industrial Technology, 2004, IEEE ICIT'04, Hammamet, Tunisia, 8-10 December 2004; Volume 3, pp. 1543-1548.

131. Guzey, H.M.; Dierks, T.; Jagannathan, S.; Acar, L. Modified consensus-based output feedback control of quadrotor UAV formations using neural networks. J. Intell. Robot. Syst. 2019, 94, 283-300. [CrossRef]

132. Hamadi, A.M. Autonomous Quadrotor Control Using Convolutional Neural Networks. 2019. Available online: https:// scholarworks.rit.edu/theses/9995/ (accessed on 30 April 2021). 
133. Islam, M.; Okasha, M.; Sulaeman, E.; Fatai, S.; Legowo, A. Performance evaluation of linear quadratic regulator and linear quadratic gaussian controllers on quadrotor platform. Int. J. Recent Technol. Eng. 2019, 7, 191-195.

134. Garcia, R.; Rubio, F.; Ortega, M. Robust PID control of the quadrotor helicopter. IFAC Proc. Vol. 2012, 45, 229-234. [CrossRef]

135. Tao, Y.; Xie, G.; Chen, Y.; Xiong, H.; Liu, H.; Zheng, J.; Gao, J. A PID and fuzzy logic based method for Quadrotor aircraft control motion. J. Intell. Fuzzy Syst. 2016, 31, 2975-2983. [CrossRef]

136. Gautam, D.; Ha, C. Control of a quadrotor using a smart self-tuning fuzzy PID controller. Int. J. Adv. Robot. Syst. 2013, 10, 380. [CrossRef]

137. Li, Y.; Song, S. Hovering control for quadrotor unmanned helicopter based on fuzzy self-tuning PID algorithm. Control Eng. China 2013, 20, 910-914.

138. Gao, W.N.; Fan, J.L.; Li, Y.N. Research on neural network pid control algorithm for a quadrotor. In Applied Mechanics and Materials; Trans Tech Publications Ltd.: Bäch, Switzerland, 2015; Volume 719, pp. 346-351.

139. Muliadi, J.; Kusumoputro, B. Neural network control system of UAV altitude dynamics and its comparison with the PID control system. J. Adv. Transp. 2018, 2018, 3823201. [CrossRef]

140. Chen, Y.m.; He, Y.l.; Zhou, M.f. Decentralized PID neural network control for a quadrotor helicopter subjected to wind disturbance. J. Cent. South Univ. 2015, 22, 168-179. [CrossRef]

141. Chen, Y.; He, Y.; Kong, L.; Zhou, M. Decentralized PID neural network control for a quadrotor helicopter. J. Chin. Inert. Technol. 2014, 22, 185-190.

142. Zhou, Q.L.; Zhang, Y.; Rabbath, C.A.; Theilliol, D. Design of feedback linearization control and reconfigurable control allocation with application to a quadrotor UAV. In Proceedings of the 2010 Conference on Control and Fault-Tolerant Systems (SysTol), Nice, France, 6-8 October 2010; pp. 371-376.

143. Zhang, D.; Qi, H.; Wu, X.; Xie, Y.; Xu, J. The quadrotor dynamic modeling and indoor target tracking control method. Math. Probl. Eng. 2014, 2014, 637034. [CrossRef]

144. Mian, A.A.; Daobo, W. Modeling and backstepping-based nonlinear control strategy for a 6 DOF quadrotor helicopter. Chin. J. Aeronaut. 2008, 21, 261-268. [CrossRef]

145. Colorado, J.; Barrientos, A.; Martinez, A.; Lafaverges, B.; Valente, J. Mini-quadrotor attitude control based on Hybrid Backstepping \& Frenet-Serret theory. In Proceedings of the 2010 IEEE International Conference on Robotics and Automation, Anchorage, AK, USA, 3-7 May 2010; pp. 1617-1622.

146. Mian, A.A.; Ahmad, M.I.; Wang, D. Backstepping based PID control strategy for an underactuated aerial robot. IFAC Proc. Vol. 2008, 41, 15636-15641. [CrossRef]

147. Tuan, L.L.; Won, S. PID based sliding mode controller design for the micro quadrotor. In Proceedings of the 201313 th International Conference on Control, Automation and Systems (ICCAS 2013), Gwangju, Korea, 20-23 October 2013; pp. $1860-1865$.

148. Bouzid, Y.; Siguerdidjane, H.; Bestaoui, Y. Sliding modes based nonlinear PID controller for quadrotor: Theory and experiment. In Proceedings of the 14th International Conference on Informatics in Control, Automation and Robotics (ICINCO 2017), Madrid, Spain, 26-28 July 2017; Volume 1, p. 286.

149. Goodarzi, F.; Lee, D.; Lee, T. Geometric nonlinear PID control of a quadrotor UAV on SE (3). In Proceedings of the 2013 European control conference (ECC), Zurich, Switzerland, 17-19 July 2013; pp. 3845-3850.

150. Kaiyuan, S.J.F.P.C. Attitude control of quadrotor aircraft via nonlinear PID. J. Beijing Univ. Aeronaut. Astronaut. $2011,9,1054$.

151. Bani Milhim, A.; Zhang, Y.; Rabbath, C.A. Quad-Rotor UAV: High-Fidelity Modeling and Nonlinear PID Control. In Proceedings of the AIAA Modeling and Simulation Technologies Conference, Toronto, ON, Canada, 2-5 August 2010; p. 8362.

152. Gonzalez-Vazquez, S.; Moreno-Valenzuela, J. A new nonlinear PI/PID controller for quadrotor posture regulation. In Proceedings of the 2010 IEEE Electronics, Robotics and Automotive Mechanics Conference, Cuernavaca, Mexico, 28 September-1 October 2010; pp. 642-647.

153. Moreno-Valenzuela, J.; Pérez-Alcocer, R.; Guerrero-Medina, M.; Dzul, A. Nonlinear PID-type controller for quadrotor trajectory tracking. IEEE/ASME Trans. Mechatron. 2018, 23, 2436-2447. [CrossRef]

154. Szafranski, G.; Czyba, R. Different Approaches of PID Control UAV Type Quadrotor. 2011. Available online: http:/ /www.imavs org/papers2011/73_IMAV2011_Summer_Proceedings.pdf (accessed on 30 April 2021).

155. Ren, J.; Liu, D.X.; Li, K.; Liu, J.; Feng, Y.; Lin, X. Cascade PID controller for quadrotor. In Proceedings of the 2016 IEEE International Conference on Information and Automation (ICIA), Ningbo, China, 1-3 August 2016; pp. 120-124.

156. Zhu, J.; Liu, E.; Guo, S.; Xu, C. A gradient optimization based PID tuning approach on quadrotor. In Proceedings of the 27th Chinese Control and Decision Conference (2015 CCDC), Qingdao, China, 23-25 May 2015; pp. 1588-1593.

157. Kim, J.; Wilkerson, S.A.; Gadsden, S.A. Comparison of gradient methods for gain tuning of a PD controller applied on a quadrotor system. In Unmanned Systems Technology XVIII; International Society for Optics and Photonics: Washington, DC, USA, 2016; Volume 9837, p. 98370V.

158. Mohammed, M.J.; Rashid, M.T.; Ali, A.A. Design optimal PID controller for quad rotor system. Int. J. Comput. Appl. 2014, $106,15-20$.

159. Babu, V.M.; Das, K.; Kumar, S. Designing of self tuning PID controller for AR drone quadrotor. In Proceedings of the 201718 th International Conference on Advanced Robotics (ICAR), Hong Kong, China, 10-12 July 2017; pp. 167-172.

160. Alkamachi, A.; Erçelebi, E. Modelling and genetic algorithm based-PID control of H-shaped racing quadcopter. Arab. J. Sci. Eng. 2017, 42, 2777-2786. [CrossRef] 
161. Bolandi, H.; Rezaei, M.; Mohsenipour, R.; Nemati, H.; Smailzadeh, S.M. Attitude Control of a Quadrotor with Optimized PID Controller. 2013. Available online: https://www.scirp.org/pdf/ica_2013080911251379.pdf (accessed on 30 April 2021).

162. Jiahe, F.; Rui, L. Fractional PID and backstepping control for a small quadrotor helicopter. In Proceedings of the 201534 th Chinese Control Conference (CCC), Hangzhou, China, 28-30 July 2015; pp. 5701-5706.

163. Pipatpaibul, P.i.; Ouyang, P. Application of online iterative learning tracking control for quadrotor UAVs. Int. Sch. Res. Not. 2013, 2013. [CrossRef]

164. Xu, D.; Whidborne, J.F.; Cooke, A. Fault tolerant control of a quadrotor using C 1 adaptive control. Int. J. Intell. Unmanned Syst. 2016, 4, 43-66. [CrossRef]

165. Shulong, Z.; Honglei, A.; Daibing, Z.; Lincheng, S. A new feedback linearization lqr control for attitude of quadrotor. In Proceedings of the 2014 13th International Conference on Control Automation Robotics \& Vision (ICARCV), Singapore, 10-12 December 2014; pp. 1593-1597.

166. Honglei, A.; Jie, L.; Jian, W.; Jianwen, W.; Hongxu, M. Backstepping-based inverse optimal attitude control of quadrotor. Int. J. Adv. Robot. Syst. 2013, 10, 223. [CrossRef]

167. Öner, K.T.; Çetinsoy, E.; Sırımoğlu, E.; Hancer, C.; Ayken, T.; Ünel, M. LQR and SMC Stabilization of a New Unmanned Aerial Vehicle. 2009. Available online: http:/ / research.sabanciuniv.edu/12653/1/v58-94.pdf (accessed on 30 April 2021).

168. Liu, Z.; Yuan, C.; Zhang, Y.; Luo, J. A learning-based fuzzy lqr control scheme for height control of an unmanned quadrotor helicopter. In Proceedings of the 2014 International Conference on Unmanned Aircraft Systems (ICUAS), Orlando, FL, USA, 27-30 May 2014; pp. 936-941.

169. Bansal, S.; Akametalu, A.K.; Jiang, F.J.; Laine, F.; Tomlin, C.J. Learning quadrotor dynamics using neural network for flight control. In Proceedings of the 2016 IEEE 55th Conference on Decision and Control (CDC), Las Vegas, NV, USA, 12-14 December 2016; pp. 4653-4660.

170. Suicmez, E.C.; Kutay, A.T. Optimal path tracking control of a quadrotor UAV. In Proceedings of the 2014 International Conference on Unmanned Aircraft Systems (ICUAS), Orlando, FL, USA, 27-30 May 2014; pp. 115-125.

171. Henriques, B.S.M. Estimation and Control of a Quadrotor Attitude. Master's Thesis, Instituto Superior Técnico, Lisbon University, Lisbon, Portugal, 2011.

172. Zhang, K.; Chen, J.; Chang, Y.; Shi, Y. EKF-based LQR tracking control of a quadrotor helicopter subject to uncertainties. In Proceedings of the IECON 2016-42nd Annual Conference of the IEEE Industrial Electronics Society, Florence, Italy, 23-26 October 2016; pp. $5426-5431$.

173. Kodgirwar, V.; Kumar, V.; Sawant, S.; Shegokar, M. Design of control system for quadcopter using Complementary Filter and PID controller. Int. J. Eng. Res. Technol. 2014, 3, 2278-0181.

174. Joyo, M.K.; Ahmed, S.F.; Hazry, D.; Tanveer, M.H.; Warsi, F.A. Position controller design for quad-rotor under perturbed condition. Wulfenia J. 2013, 20, 178-189.

175. Cowling, I.D.; Whidborne, J.F.; Cooke, A.K. Optimal trajectory planning and LQR control for a quadrotor UAV. In Proceedings of the International Conference on Control, Cranfield University, Bedford, UK, 30 August-1 September 2006.

176. Mu, B.; Shi, Y. Distributed LQR consensus control for heterogeneous multiagent systems: Theory and experiments. IEEE/ASME Trans. Mechatron. 2018, 23, 434-443. [CrossRef]

177. Sun, Y.; Xian, N.; Duan, H. Linear-quadratic regulator controller design for quadrotor based on pigeon-inspired optimization. Aircr. Eng. Aerosp. Technol. 2016, 88, 761-770. [CrossRef]

178. van den Berg, J. Extended LQR: Locally-optimal feedback control for systems with non-linear dynamics and non-quadratic cost. In Robotics Research; Springer: Berlin/Heidelberg, Germany, 2016; pp. 39-56.

179. Ryan, T.; Kim, H.J. PD-Tunable H $\infty$ Control Design for a Quadrotor. In Proceedings of the AIAA Guidance, Navigation, and Control (GNC) Conference, Boston, MA, USA, 19-22 August 2013; p. 4530.

180. Mokhtari, A.; Benallegue, A.; Daachi, B. Robust feedback linearization and GH/sub/spl infin//controller for a quadrotor unmanned aerial vehicle. In Proceedings of the 2005 IEEE/RSJ International Conference on Intelligent Robots and Systems, Edmonton, AB, Canada, 2-6 August 2005; pp. 1198-1203.

181. Mukherjee, P.; Waslander, S. Direct adaptive feedback linearization for quadrotor control. In Proceedings of the AIAA Guidance, Navigation, and Control Conference, Minneapolis, MN, USA, 13-16 August 2012; p. 4917.

182. Choi, I.; Bang, H. Quadrotor-tracking controller design using adaptive dynamic feedback-linearization method. Proc. Inst. Mech. Eng. Part G J. Aerosp. Eng. 2014, 228, 2329-2342. [CrossRef]

183. Benallegue, A.; Mokhtari, A.; Fridman, L. Feedback linearization and high order sliding mode observer for a quadrotor UAV. In Proceedings of the International Workshop on Variable Structure Systems, 2006, VSS'06, Alghero, Italy, 5-7 June 2006; pp. 365-372.

184. Al-Hiddabi, S.A. Quadrotor control using feedback linearization with dynamic extension. In Proceedings of the 20096 th International Symposium on Mechatronics and Its Applications, Sharjah, United Arab Emirates, 23-26 March 2009; pp. 1-3.

185. Sydney, N.; Smyth, B.; Paley, D.A. Dynamic control of autonomous quadrotor flight in an estimated wind field. In Proceedings of the 52nd IEEE Conference on Decision and Control, Firenze, Italy, 10-13 December 2013; pp. 3609-3616.

186. Aboudonia, A.; El-Badawy, A.; Rashad, R. Disturbance observer-based feedback linearization control of an unmanned quadrotor helicopter. Proc. Inst. Mech. Eng. Part I J. Syst. Control Eng. 2016, 230, 877-891. [CrossRef]

187. Lee, K.; Back, J.; Choy, I. Nonlinear disturbance observer based robust attitude tracking controller for quadrotor UAVs. Int. J. Control Autom. Syst. 2014, 12, 1266-1275. [CrossRef] 
188. Mian, A.A.; Wang, D.b. Dynamic modeling and nonlinear control strategy for an underactuated quad rotor rotorcraft. J. Zhejiang Univ. Sci. A 2008, 9, 539-545. [CrossRef]

189. Kim, H.K.; Nguyen, T.T.; Oh, S.J.; Kim, S.B. Position control of a small scale quadrotor using block feedback linearization control. In AETA 2013: Recent Advances in Electrical Engineering and Related Sciences; Springer: Berlin/Heidelberg, Germany, 2014; pp. 525-534.

190. Mahmood, A.; Kim, Y. Decentrailized formation flight control of quadcopters using robust feedback linearization. J. Frankl. Inst. 2017, 354, 852-871. [CrossRef]

191. Das, A.; Lewis, F.; Subbarao, K. Backstepping approach for controlling a quadrotor using lagrange form dynamics. J. Intell. Robot. Syst. 2009, 56, 127-151. [CrossRef]

192. Mohd Basri, M.A.; Husain, A.R.; Danapalasingam, K.A. Intelligent adaptive backstepping control for MIMO uncertain non-linear quadrotor helicopter systems. Trans. Inst. Meas. Control 2015, 37, 345-361. [CrossRef]

193. Bouadi, H.; Bouchoucha, M.; Tadjine, M. Sliding mode control based on backstepping approach for an UAV type-quadrotor. World Acad. Sci. Eng. Technol. 2007, 26, 22-27.

194. Chen, F.; Jiang, R.; Zhang, K.; Jiang, B.; Tao, G. Robust backstepping sliding-mode control and observer-based fault estimation for a quadrotor UAV. IEEE Trans. Ind. Electron. 2016, 63, 5044-5056. [CrossRef]

195. Madani, T.; Benallegue, A. Backstepping control with exact 2-sliding mode estimation for a quadrotor unmanned aerial vehicle. In Proceedings of the 2007 IEEE/RSJ International Conference on Intelligent Robots and Systems, San Diego, CA, USA, 29 October-2 November 2007; pp. 141-146.

196. Nadda, S.; Swarup, A. Development of backstepping based sliding mode control for a quadrotor. In Proceedings of the 2014 IEEE 10th International Colloquium on Signal Processing and Its Applications, Kuala Lumpur, Malaysia, 7-9 March $2014 ;$ pp. 10-13.

197. Antonio-Toledo, M.E.; Sanchez, E.N.; Alanis, A.Y.; Flórez, J.; Perez-Cisneros, M.A. Real-time integral backstepping with sliding mode control for a quadrotor UAV. IFAC-PapersOnLine 2018, 51, 549-554. [CrossRef]

198. Ramirez-Rodriguez, H.; Parra-Vega, V.; Sanchez-Orta, A.; Garcia-Salazar, O. Robust backstepping control based on integral sliding modes for tracking of quadrotors. J. Intell. Robot. Syst. 2014, 73, 51-66. [CrossRef]

199. Jia, Z.; Yu, J.; Mei, Y.; Chen, Y.; Shen, Y.; Ai, X. Integral backstepping sliding mode control for quadrotor helicopter under external uncertain disturbances. Aerosp. Sci. Technol. 2017, 68, 299-307. [CrossRef]

200. Zeghlache, S.; Saigaa, D.; Harrag, A.; Kara, K.; Bouguerra, A. Backstepping sliding mode controller improved with fuzzy logic: Application to the quadrotor helicopter. Arch. Control Sci. 2012, 22, 315-342. [CrossRef]

201. Khebbache, H.; Tadjine, M. Robust fuzzy backstepping sliding mode controller for a quadrotor unmanned aerial vehicle. J. Control Eng. Appl. Inform. 2013, 15, 3-11.

202. Basri, M.A.M.; Husain, A.R.; Danapalasingam, K.A. Enhanced backstepping controller design with application to autonomous quadrotor unmanned aerial vehicle. J. Intell. Robot. Syst. 2015, 79, 295-321. [CrossRef]

203. Zuo, Z. Trajectory tracking control design with command-filtered compensation for a quadrotor. IET Control Theory Appl. 2010, 4, 2343-2355. [CrossRef]

204. Gong, X.; Bai, Y.; Peng, C.; Zhao, C.; Tian, Y. Trajectory tracking control of a quad-rotor UAV based on command filtered backstepping. In Proceedings of the 2012 Third International Conference on Intelligent Control and Information Processing, Dalian, China, 15-17 July 2012; pp. 179-184.

205. Jasim, W.; Gu, D. Integral backstepping controller for quadrotor path tracking. In Proceedings of the 2015 International Conference on Advanced Robotics (ICAR), Istanbul, Turkey, 27-31 July 2015; pp. 593-598.

206. Poultney, A.; Gong, P.; Ashrafiuon, H. Integral backstepping control for trajectory and yaw motion tracking of quadrotors. Robotica 2019, 37, 300. [CrossRef]

207. Chen, F.; Lei, W.; Zhang, K.; Tao, G.; Jiang, B. A novel nonlinear resilient control for a quadrotor UAV via backstepping control and nonlinear disturbance observer. Nonlinear Dyn. 2016, 85, 1281-1295. [CrossRef]

208. Pollini, L.; Metrangolo, A. Simulation and robust backstepping control of a quadrotor aircraft. In Proceedings of the AIAA Modeling and Simulation Technologies Conference and Exhibit, Honolulu, HI, USA, 18-21 August 2008; p. 6363.

209. Regula, G.; Lantos, B. Backstepping based control design with state estimation and path tracking to an indoor quadrotor helicopter. Period. Polytech. Electr. Eng. 2009, 53, 151-161. [CrossRef]

210. Aboudonia, A.; El-Badawy, A.; Rashad, R. Active anti-disturbance control of a quadrotor unmanned aerial vehicle using the command-filtering backstepping approach. Nonlinear Dyn. 2017, 90, 581-597. [CrossRef]

211. Li, C.; Zhang, Y.; Li, P. Full control of a quadrotor using parameter-scheduled backstepping method: Implementation and experimental tests. Nonlinear Dyn. 2017, 89, 1259-1278. [CrossRef]

212. Zhen, H.; Qi, X.; Dong, H. An adaptive block backstepping controller for attitude stabilization of a quadrotor helicopter. WSEAS Trans. Syst. Control 2013, 8, 46-55.

213. Mohd Basri, M.A.; Husain, A.R.; Danapalasingam, K.A. A hybrid optimal backstepping and adaptive fuzzy control for autonomous quadrotor helicopter with time-varying disturbance. Proc. Inst. Mech. Eng. Part G J. Aerosp. Eng. 2015, 229, 2178-2195. [CrossRef]

214. Shao, X.; Liu, J.; Wang, H. Robust back-stepping output feedback trajectory tracking for quadrotors via extended state observer and sigmoid tracking differentiator. Mech. Syst. Signal Process. 2018, 104, 631-647. [CrossRef] 
215. Wang, R.; Liu, J. Trajectory tracking control of a 6-DOF quadrotor UAV with input saturation via backstepping. J. Frankl. Inst. 2018, 355, 3288-3309. [CrossRef]

216. Lee, K.U.; Choi, Y.H.; Park, J.B. Backstepping based formation control of quadrotors with the state transformation technique. Appl. Sci. 2017, 7, 1170. [CrossRef]

217. Rosaldo-Serrano, M.A.; Santiaguillo-Salinas, J.; Aranda-Bricaire, E. Observer-based time-varying backstepping control for a quadrotor multi-agent system. J. Intell. Robot. Syst. 2019, 93, 135-150. [CrossRef]

218. Patel, A.R.; Patel, M.A.; Vyas, D.R. Modeling and analysis of quadrotor using sliding mode control. In Proceedings of the 2012 44th Southeastern Symposium on System Theory (SSST), Jacksonville, FL, USA, 11-13 March 2012; pp. 111-114.

219. Herrera, M.; Chamorro, W.; Gómez, A.P.; Camacho, O. Sliding mode control: An approach to control a quadrotor. In Proceedings of the 2015 Asia-Pacific Conference on Computer Aided System Engineering, Quito, Ecuador, 14-16 July 2015 ; pp. 314-319.

220. Fang, Z.; Zhi, Z.; Jun, L.; Jian, W. Feedback linearization and continuous sliding mode control for a quadrotor UAV. In Proceedings of the 2008 27th Chinese Control Conference, Kunming, China, 16-18 July 2008; pp. 349-353.

221. Gong, X.; Hou, Z.C.; Zhao, C.J.; Bai, Y.; Tian, Y.T. Adaptive backstepping sliding mode trajectory tracking control for a quad-rotor. Int. J. Autom. Comput. 2012, 9, 555-560. [CrossRef]

222. Besnard, L.; Shtessel, Y.B.; Landrum, B. Quadrotor vehicle control via sliding mode controller driven by sliding mode disturbance observer. J. Frankl. Inst. 2012, 349, 658-684. [CrossRef]

223. Bouadi, H.; Tadjine, M. Nonlinear observer design and sliding mode control of four rotors helicopter. Int. J. Mech. Aerospace Ind. Mechatron. Manuf. Eng. 2007, 1, 354-359.

224. Efe, M.Ö. Integral sliding mode control of a quadrotor with fractional order reaching dynamics. Trans. Inst. Meas. Control 2011, 33, 985-1003. [CrossRef]

225. Zhao, L.; Dai, L.; Xia, Y.; Li, P. Attitude control for quadrotors subjected to wind disturbances via active disturbance rejection control and integral sliding mode control. Mech. Syst. Signal Process. 2019, 129, 531-545. [CrossRef]

226. Zheng, E.H.; Xiong, J.J.; Luo, J.L. Second order sliding mode control for a quadrotor UAV. ISA Trans. 2014, 53, 1350-1356. [CrossRef] [PubMed]

227. Muñoz, F.; González-Hernández, I.; Salazar, S.; Espinoza, E.S.; Lozano, R. Second order sliding mode controllers for altitude control of a quadrotor UAS: Real-time implementation in outdoor environments. Neurocomputing 2017, 233, 61-71. [CrossRef]

228. Luque-Vega, L.; Castillo-Toledo, B.; Loukianov, A.G. Robust block second order sliding mode control for a quadrotor. J. Frankl. Inst. 2012, 349, 719-739. [CrossRef]

229. Bouadi, H.; Cunha, S.S.; Drouin, A.; Mora-Camino, F. Adaptive sliding mode control for quadrotor attitude stabilization and altitude tracking. In Proceedings of the 2011 IEEE 12th International Symposium on Computational Intelligence and Informatics (CINTI), Budapest, Hungary, 21-22 November 2011; pp. 449-455.

230. Xiong, J.J.; Zhang, G.B. Global fast dynamic terminal sliding mode control for a quadrotor UAV. ISA Trans. 2017, 66, 233-240. [CrossRef]

231. Sumantri, B.; Uchiyama, N.; Sano, S. Least square based sliding mode control for a quad-rotor helicopter and energy saving by chattering reduction. Mech. Syst. Signal Process. 2016, 66, 769-784. [CrossRef]

232. Zhao, B.; Xian, B.; Zhang, Y.; Zhang, X. Nonlinear robust sliding mode control of a quadrotor unmanned aerial vehicle based on immersion and invariance method. Int. J. Robust Nonlinear Control 2015, 25, 3714-3731. [CrossRef]

233. Li, S.; Li, B.; Geng, Q. Adaptive sliding mode control for quadrotor helicopters. In Proceedings of the 33rd Chinese Control Conference, Nanjing, China, 28-30 July 2014; pp. 71-76.

234. González, I.; Salazar, S.; Lozano, R. Chattering-free sliding mode altitude control for a quad-rotor aircraft: Real-time application. J. Intell. Robot. Syst. 2014, 73, 137-155. [CrossRef]

235. Izaguirre-Espinosa, C.; Muñoz-Vázquez, A.J.; Sánchez-Orta, A.; Parra-Vega, V.; Castillo, P. Attitude control of quadrotors based on fractional sliding modes: Theory and experiments. IET Control Theory Appl. 2016, 10, 825-832. [CrossRef]

236. Tanveer, M.H.; Hazry, D.; Ahmed, S.F.; Joyo, M.K.; Warsi, F.A.; Kamaruddin, H.; Razlan, Z.M.; Wan, K.; Shahriman, A. NMPC-PID based control structure design for avoiding uncertainties in attitude and altitude tracking control of quad-rotor (UAV). In Proceedings of the 2014 IEEE 10th International Colloquium on Signal Processing and Its Applications, Kuala Lumpur, Malaysia, 7-9 March 2014; pp. 117-122.

237. Mousavi, M.A.; Heshmati, Z.; Moshiri, B. LTV-MPC based path planning of an autonomous vehicle via convex optimization. In Proceedings of the 2013 21st Iranian Conference on Electrical Engineering (ICEE), Mashhad, Iran, 14-16 May 2013; pp. 1-7.

238. Diwu, P.J.; Yang, S.X. MPC/SMC Control for a Quadrotor's Trajectory Tracking. Trans. Beijing Inst. Technol. $2013,33,505-509$.

239. Aswani, A.; Bouffard, P.; Tomlin, C. Extensions of learning-based model predictive control for real-time application to a quadrotor helicopter. In Proceedings of the 2012 American Control Conference (ACC), Montreal, QC, Canada, 27-29 June 2012; pp. $4661-4666$.

240. Cao, G.; Lai, E.M.K.; Alam, F. Gaussian process model predictive control of an unmanned quadrotor. J. Intell. Robot. Syst. 2017, 88, 147-162. [CrossRef]

241. Alexis, K.; Papachristos, C.; Siegwart, R.; Tzes, A. Robust model predictive flight control of unmanned rotorcrafts. J. Intell. Robot. Syst. 2016, 81, 443-469. [CrossRef]

242. Mueller, M.W.; D'Andrea, R. A model predictive controller for quadrocopter state interception. In Proceedings of the 2013 European Control Conference (ECC), Zurich, Switzerland, 17-19 July 2013; pp. 1383-1389. 
243. Liu, C.; Chen, W.H.; Andrews, J. Tracking control of small-scale helicopters using explicit nonlinear MPC augmented with disturbance observers. Control Eng. Pract. 2012, 20, 258-268. [CrossRef]

244. Alexis, K.; Nikolakopoulos, G.; Tzes, A. Switching model predictive attitude control for a quadrotor helicopter subject to atmospheric disturbances. Control Eng. Pract. 2011, 19, 1195-1207. [CrossRef]

245. Abdolhosseini, M.; Zhang, Y.; Rabbath, C.A. An efficient model predictive control scheme for an unmanned quadrotor helicopter. J. Intell. Robot. Syst. 2013, 70, 27-38. [CrossRef]

246. Chen, X.; Wang, L. Cascaded model predictive control of a quadrotor UAV. In Proceedings of the 2013 Australian Control Conference, Fremantle, WA, Australia, 4-5 November 2013; pp. 354-359.

247. Bemporad, A.; Rocchi, C. Decentralized hybrid model predictive control of a formation of unmanned aerial vehicles. IFAC Proc. Vol. 2011, 44, 11900-11906. [CrossRef]

248. Ru, P.; Subbarao, K. Nonlinear model predictive control for unmanned aerial vehicles. Aerospace 2017, 4, 31. [CrossRef]

249. Novák, J.; Chalupa, P. Implementation aspects of embedded MPC with fast gradient method. Int. J. Circuits Syst. Signal Process. 2014, 8, 504-511.

250. Greatwood, C.; Richards, A.G. Reinforcement learning and model predictive control for robust embedded quadrotor guidance and control. Auton. Robot. 2019, 43, 1681-1693. [CrossRef]

251. Egardt, B. Stability of Adaptive Controllers; Springer: Berlin/Heidelberg, Germany, 1979; Volume 20.

252. Nicol, C.; Macnab, C.; Ramirez-Serrano, A. Robust adaptive control of a quadrotor helicopter. Mechatronics 2011, 21, 927-938. [CrossRef]

253. Narendra, K.; Annaswamy, A. A new adaptive law for robust adaptation without persistent excitation. IEEE Trans. Autom. Control 1987, 32, 134-145. [CrossRef]

254. Michini, B.; How, J. L1 adaptive control for indoor autonomous vehicles: Design process and flight testing. In Proceedings of the AIAA Guidance, Navigation, and Control Conference, Chicago, IL, USA, 10-13 August 2009; p. 5754.

255. De Monte, P.; Lohmann, B. Position trajectory tracking of a quadrotor helicopter based on L1 adaptive control. In Proceedings of the 2013 European Control Conference (ECC), Zurich, Switzerland, 17-19 July 2013; pp. 3346-3353.

256. Zuo, Z. Adaptive trajectory tracking control design with command filtered compensation for a quadrotor. J. Vib. Control 2013, 19, 94-108. [CrossRef]

257. Selfridge, J.M.; Tao, G. A multivariable adaptive controller for a quadrotor with guaranteed matching conditions. Syst. Sci. Control Eng. Open Access J. 2014, 2, 24-33. [CrossRef]

258. Kun, D.W.; Hwang, I. Linear matrix inequality-based nonlinear adaptive robust control of quadrotor. J. Guid. Control Dyn. 2016, 39, 996-1008. [CrossRef]

259. Erginer, B.; Altuğ, E. Design and implementation of a hybrid fuzzy logic controller for a quadrotor VTOL vehicle. Int. J. Control Autom. Syst. 2012, 10, 61-70. [CrossRef]

260. Zareb, M.; Ayad, R.; Nouibat, W. Fuzzy-PID hybrid control system to navigate an autonomous mini-Quadrotor. In Proceedings of the 3rd International Conference on Systems and Control, Algiers, Algeria, 29-31 October 2013; pp. $906-913$.

261. Zeghlache, S.; Saigaa, D.; Kara, K.; Harrag, A.; Bouguerra, A. Fuzzy sliding mode control with chattering elimination for a quadrotor helicopter in vertical flight. In Proceedings of the International Conference on Hybrid Artificial Intelligence Systems; Springer: Berlin/Heidelberg, Germany, 2012; pp. 125-136.

262. Al-Younes, Y.; Jarrah, M. Attitude stabilization of quadrotor UAV using backstepping fuzzy logic \& backstepping least-meansquare controllers. In Proceedings of the 2008 5th International Symposium on Mechatronics and Its Applications, Amman, Jordan, 27-29 May 2008; pp. 1-11.

263. Bhatkhande, P.; Havens, T.C. Real time fuzzy controller for quadrotor stability control. In Proceedings of the 2014 IEEE International Conference on Fuzzy Systems (FUZZ-IEEE), Beijing, China, 6-11 July 2014; pp. 913-919.

264. Chen, X.; Li, D.; Bai, Y.; Xu, Z. Modeling and neuro-fuzzy adaptive attitude control for eight-Rotor MAV. Int. J. Control Autom. Syst. 2011, 9, 1154-1163. [CrossRef]

265. Chen, X.J.; Li, D.; Bai, Y.; Xu, Z.J. Application of type-II fuzzy neural network to adaptive double axis motion control system. Opt. Precis. Eng. 2011, 19, 1643-1650. [CrossRef]

266. Sheikhpour, S.; Shouraki, S.B. A model-based fuzzy controller using the parallel distributed compensation method for quadrotor attitude stabilization. In Proceedings of the 2013 21st Iranian Conference on Electrical Engineering (ICEE), Mashhad, Iran, 14-16 May 2013; pp. 1-6.

267. Wahyunggoro, O.; Cahyadi, A.I. Quadrotor Path Planning Based On Modified Fuzzy Cell Decomposition Algorithm. Telkomnika 2016, 14, 655-664.

268. Torres, F.; Rabhi, A.; Lara, D.; Romero, G.; Pégard, C. Fuzzy state feedback for attitude stabilization of quadrotor. Int. J. Adv. Robot. Syst. 2016, 13, 2. [CrossRef]

269. Szlachetko, B.; Lower, M. On quadrotor navigation using fuzzy logic regulators. In Proceedings of the International Conference on Computational Collective Intelligence; Springer: Berlin/Heidelberg, Germany, 2012; pp. 210-219.

270. Nemes, A. Fuzzy-Genetic Control of Quadrotors Unmanned Aerial Vehicles. Interdiscip. Descr. Complex Syst. INDECS 2016, 14, 223-235. [CrossRef]

271. Pazooki, M.; Mazinan, A. Hybrid fuzzy-based sliding-mode control approach, optimized by genetic algorithm for quadrotor unmanned aerial vehicles. Complex Intell. Syst. 2018, 4, 79-93. [CrossRef] 
272. Efe, M.Ö. Neural Network Assisted Computationally Simple PI $\lambda \mathrm{D} \mu$ Control of a Quadrotor UAV. IEEE Trans. Ind. Inform. 2011, 7, 354-361. [CrossRef]

273. Zhao, D.; Sun, C.; Wang, Q.; Yang, W. Neural network based PID control for quadrotor aircraft. In Proceedings of the International Conference on Intelligent Science and Big Data Engineering; Springer: Berlin/Heidelberg, Germany, 2015; pp. $287-297$.

274. Boudjedir, H.; Yacef, F.; Bouhali, O.; Rizoug, N. Adaptive neural network for a quadrotor unmanned aerial vehicle. Int. J. Found. Comput. Sci. Technol. 2012, 2, 1-13. [CrossRef]

275. Das, A.; Lewis, F.; Subbarao, K. Dynamic Neural Network-Based Robust Backstepping Control approach for Quadrotors. In Proceedings of the AIAA Guidance, Navigation and Control Conference and Exhibit, Honolulu, HI, USA, 18-21 August 2008; p. 6780.

276. Shirzadeh, M.; Asl, H.J.; Amirkhani, A.; Jalali, A.A. Vision-based control of a quadrotor utilizing artificial neural networks for tracking of moving targets. Eng. Appl. Artif. Intell. 2017, 58, 34-48. [CrossRef]

277. Bouhali, O.; Boudjedir, H. Neural network control with neuro-sliding mode observer applied to quadrotor helicopter. In Proceedings of the 2011 International Symposium on Innovations in Intelligent Systems and Applications, Istanbul, Turkey, 15-18 June 2011; pp. 24-28.

278. Boudjedir, H.; Bouhali, O.; Rizoug, N. Neural network control based on adaptive observer for quadrotor helicopter. Int. J. Inf. Technol. Control Autom. 2012, 2, 39-54. [CrossRef]

279. Kim, B.S.; Calise, A.J. Nonlinear flight control using neural networks. J. Guid. Control. Dyn. 1997, 20, 26-33. [CrossRef]

280. Wu, J.; Peng, H.; Chen, Q.; Peng, X. Modeling and control approach to a distinctive quadrotor helicopter. ISA Trans. 2014, 53, 173-185. [CrossRef]

281. Amir, M.Y.; Abbas, V. Modeling and neural control of quad rotor helicopter. Yanbu J. Eng. Sci. 2011, 2, 35-49.

282. Shirzadeh, M.; Amirkhani, A.; Jalali, A.; Mosavi, M.R. An indirect adaptive neural control of a visual-based quadrotor robot for pursuing a moving target. ISA Trans. 2015, 59, 290-302. [CrossRef]

283. Mohajerin, N.; Waslander, S.L. Modelling a quadrotor vehicle using a modular deep recurrent neural network. In Proceedings of the 2015 IEEE International Conference on Systems, Man, and Cybernetics, Hong Kong, China, 9-12 October 2015 ; pp. 376-381.

284. Shastry, A.K.; Pattanaik, A.; Kothari, M. Neuro-adaptive augmented dynamic inversion controller for quadrotors. IFAC-PapersOnLine 2016, 49, 302-307. [CrossRef]

285. Lin, Q.; Cai, Z.; Wang, Y.; Yang, J.; Chen, L. Adaptive flight control design for quadrotor UAV based on dynamic inversion and neural networks. In Proceedings of the 2013 Third International Conference on Instrumentation, Measurement, Computer, Communication and Control, Shenyang, China, 21-23 September 2013; pp. 1461-1466. 